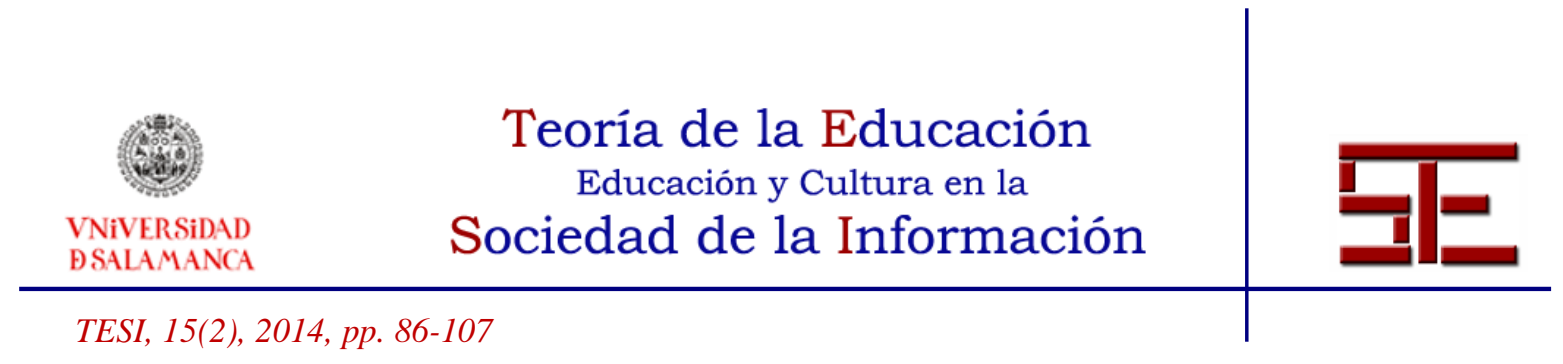

\title{
USO DE RECURSOS EDUCATIVOS ABIERTOS (REA) Y OBJETOS DE APRENDIZAJE (OA) EN EDUCACIÓN BÁSICA
}

Resumen: El presente documento tiene como objetivo presentar un estudio sobre la integración de recursos digitales abiertos como herramientas didácticas en el nivel de educación primaria. Los recursos utilizados se ubicaban en tres repositorios y un catálogo indexado de Recursos Educativos Abiertos (REA) y Objetos de Aprendizaje (OA) supervisados por tres instituciones de educación superior en México. El contexto se desarrolló en tres grupos de una escuela primaria del sector público ubicada en la zona metropolitana de Monterrey, Nuevo León, México. La metodología que se seleccionó fue de corte cualitativo con un enfoque de estudio de casos para describir los fenómenos identificados en torno a la experiencia de uso de los REA y OA y sus implicaciones en el aprendizaje activo. Los resultados dan cuenta que los docentes de la institución están familiarizados con el uso de tecnologías de información y comunicación (TIC), pero desconocen la forma de seleccionar recursos con licenciamiento abierto. El uso de los recursos digitales seleccionados les permitió a los docentes integrarlos a su práctica docente como material didáctico para reforzar conocimientos analizados en el currículo.

Palabras clave: Prácticas educativas abiertas; Recursos Educativos Abiertos; Objetos de Aprendizaje; estrategias de enseñanza-aprendizaje; aprendizaje activo.

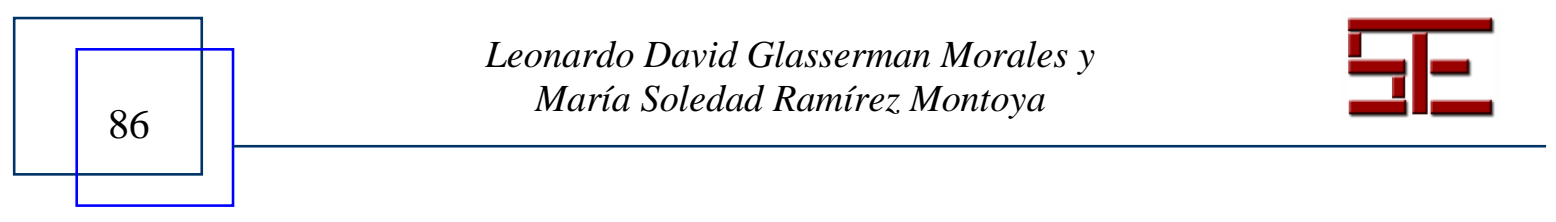




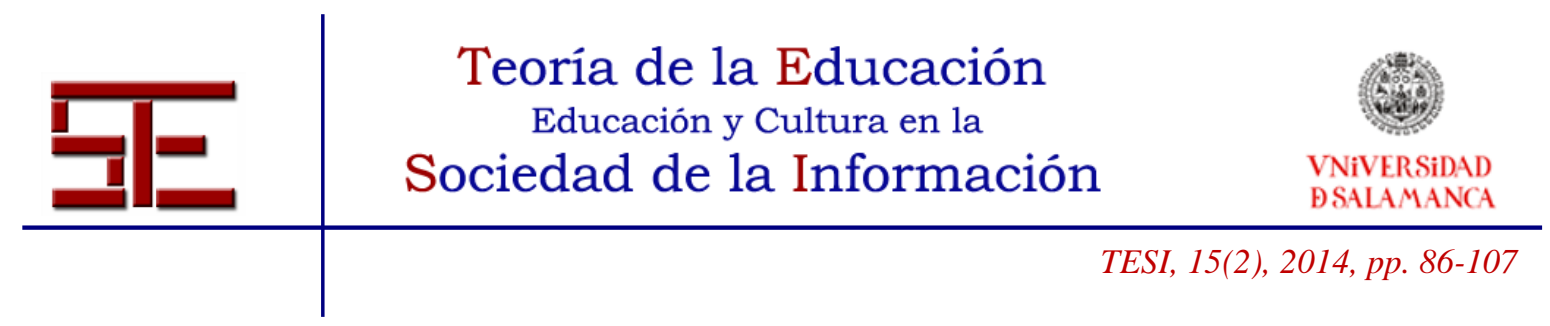

\title{
USE OF OPEN EDUCATIONAL RESOURCES (OER) AND LEARNING OBJECTS (LO) IN K12 INSTRUCTION
}

\begin{abstract}
This document aims to present a research study of open digital resources as teaching tools at the primary level. The resources were addressed in three online repositories and one indexed catalogue of OER and LO reviewed by three higher education institutions in Mexico. The study took place in three groups of a public elementary institution located in Monterrey Nuevo Leon. Qualitative research was identified to present the study and it was used a case study approach to describe the phenomena identified among the uses of OER and LO towards the active learning process. The results showed that the participant teachers have had experience on using technology inside the classroom but were unaware of the use of open resources. The use of digital resources allowed the instructors to integrate them as didactic material in order to reinforce the topics and themes along the curricula.
\end{abstract}

Key words: Open educational practices; Open Educational Resources; Learning Objects; teaching and learning strategies, active learning.

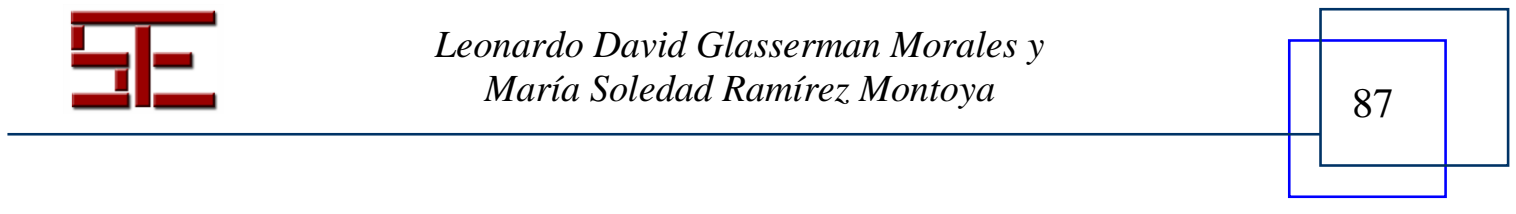




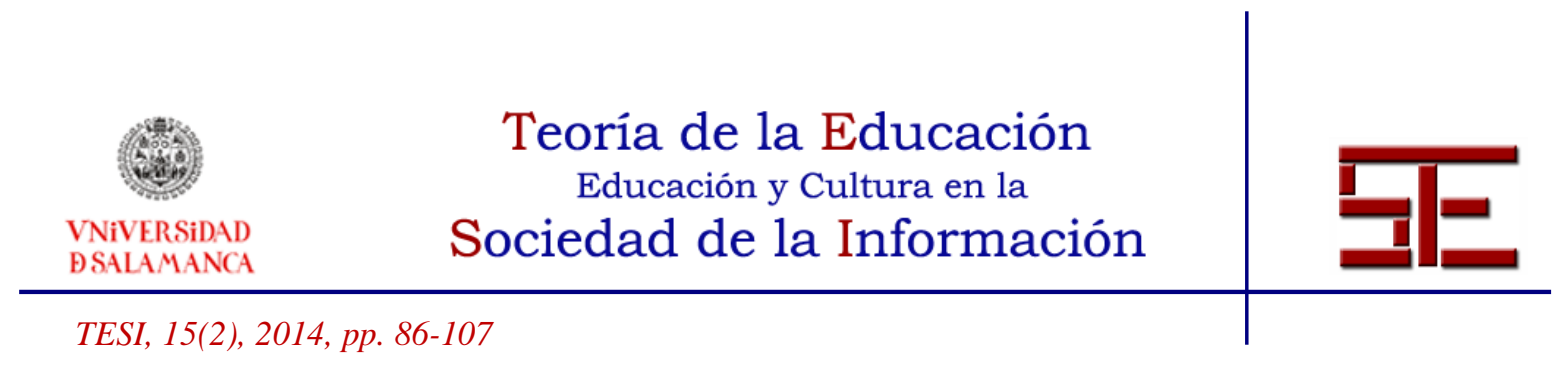

\section{USO DE RECURSOS EDUCATIVOS ABIERTOS (REA) Y OBJETOS DE APRENDIZAJE (OA) EN EDUCACIÓN BÁSICA}

Fecha de recepción: 14/02/2014; fecha de aceptación: 12/04/2014; fecha de publicación: 30/06/2014

Leonardo David Glasserman Morales

glasserman@gmail.com

Tecnológico de Monterrey

María Soledad Ramírez Montoya

solramirez@tecvirtual.mx

Tecnológico de Monterrey

Reconocimiento. Este estudio forma parte de un proyecto financiado por el fondo mixto CUDI-CONACYT 2011, titulado: Metaconector de repositorios educativos para potenciar el uso de objetos de aprendizaje y recursos educativos abiertos: mejores prácticas. Los autores agradecen el apoyo obtenido para realizar este estudio, así como a la institución participante, que fue objeto de análisis, por su disponibilidad para participar.

\section{1.- INTRODUCCIÓN}

El presente documento tiene la intención de plasmar las ideas que derivan de un macro estudio tras el desarrollo de un proyecto de investigación financiado por la Corporación de Universidades para el Desarrollo de Internet (CUDI) y el Consejo Nacional de Ciencia y Tecnología (CONACYT) en México, bajo el nombre de Metaconector de repositorios educativos para potenciar el uso de objetos de aprendizaje y recursos educativos abiertos: mejores prácticas. En el proyecto participaron instituciones de educación superior de alto reconocimiento en México como el Instituto Tecnológico y de Estudios Superiores de Monterrey (ITESM), la Universidad de Montemorelos (UM), la Universidad de Guadalajara (UdG), así como el Instituto Tecnológico de Chihuahua (ITCH).

El objetivo del estudio fue conocer la experiencia en cuanto al uso de recursos digitales abiertos como herramientas didácticas por parte de los docentes en tres diferentes grupos $\left(1^{\circ}, 5^{\circ}\right.$ y $\left.6^{\circ}\right)$ de educación primaria de la zona metropolitana de Monterrey. Lo anterior se logró a través de la observación directa de los docentes en el aula. En el documento se incluye un acercamiento a los hechos y acontecimientos que anteceden al proyecto. Posteriormente, se presenta una revisión de literatura, así como la elección de la metodología para analizar el fenómeno, el análisis de resultados, la discusión de los mismos y conclusiones finales.

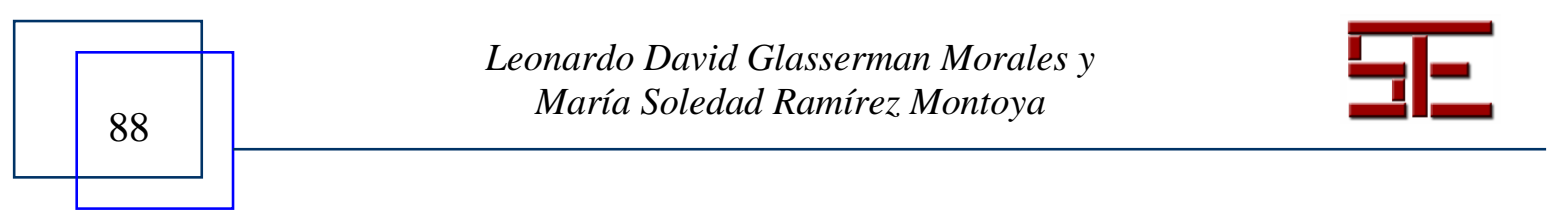




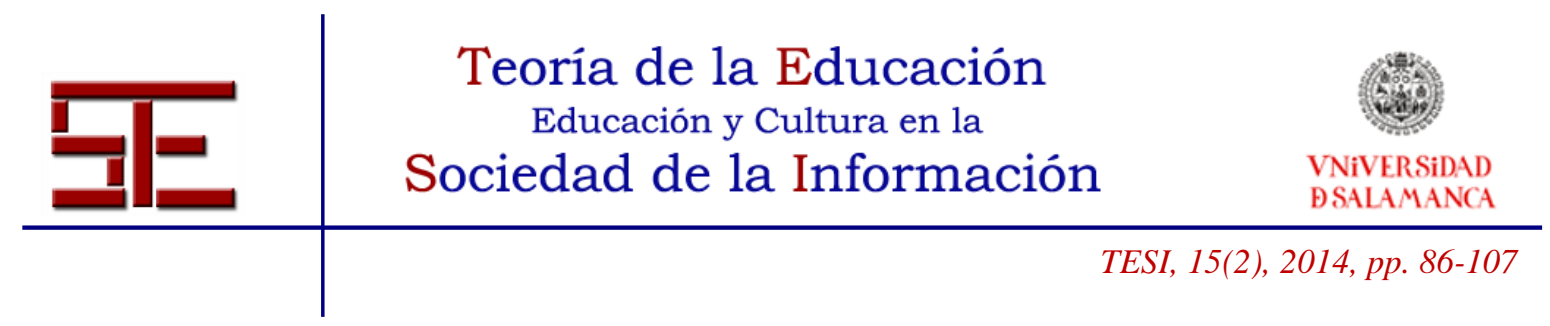

\section{2.- MARCO CONTEXTUAL Y NATURALEZA DE LA INVESTIGACIÓN}

En México, existen instituciones cuyo interés es fomentar el avance en el área de la investigación y la ciencia, como el caso del Consejo Nacional de Ciencia y Tecnología (CONACYT). De igual forma, existen órganos enfocados en agrupar y reunir el capital humano e intelectual para la generación de conocimiento en diferentes áreas de importancia, como el área educativa. Así, se encuentra en México la Corporación de Universidades para el Desarrollo de Internet A. C. (CUDI), que apoya con financiamiento a proyectos que hagan uso de las redes avanzadas para realizar investigación en diferentes áreas que conforman a la corporación.

Fue así como se aprobó un proyecto financiado por ambas instituciones, CUDI y CONACYT, en su edición 2010 para ejecutarse durante el año 2011 con el objetivo principal de analizar y conocer un primer acercamiento hacia los Recursos Educativos Abiertos (REA) y Objetos de Aprendizaje (OA) contenidos en distintos repositorios, tanto por parte de los maestros en su práctica docente, así como de los alumnos en sus procesos de aprendizaje. Los objetivos específicos que se desprenden del estudio estuvieron en función de conocer cómo tenía lugar el uso de los REA y OA como recursos para la enseñanza de contenidos académicos de nivel primaria en grados escolares considerados clave (primeros y últimos años). Asimismo, se buscaba fomentar la apropiación tecnológica en docentes para que posteriormente ellos instruyeran a sus alumnos en cuanto al uso de los repositorios que se les presentaron.

La principal meta de la investigación fue poder contar con la experiencia de uso de los REA y OA como materiales didácticos para enriquecer las clases de los profesores que participaron en el estudio y que esta experiencia sirviera como punta de lanza para el gran proyecto en la construcción de una guía de usuarios sobre el metaconector que se desarrolló. Así mismo, los resultados fueron clave para determinar que la participación en el proyecto tuvo una respuesta positiva y que se propició y generó una cultura de trabajo con recursos de calidad, que, al mismo tiempo, cumplían con estándares de licenciamiento abierto.

El estudio estuvo delimitado dentro de los tres grupos participantes y en los tres repositorios institucionales DAR (http://www.catedra.ruv.itesm.mx), CREA (http://www.crea.udg.mx/) y Laboratorio m-Learning (http://movil.itch.edu.mx/MLearning_Lab/Laboratorio_M-Learning.html), así como el catálogo de recursos indexados TEMOA (http://www.temoa.info). Se contó con un plan de trabajo para el desarrollo del macroproyecto y para efectos de este estudio se contemplaron dos fases, la primera respecto a visitas de identificación de recursos y observación de usuarios y una segunda etapa para el análisis de datos y la generación del reporte de investigación.

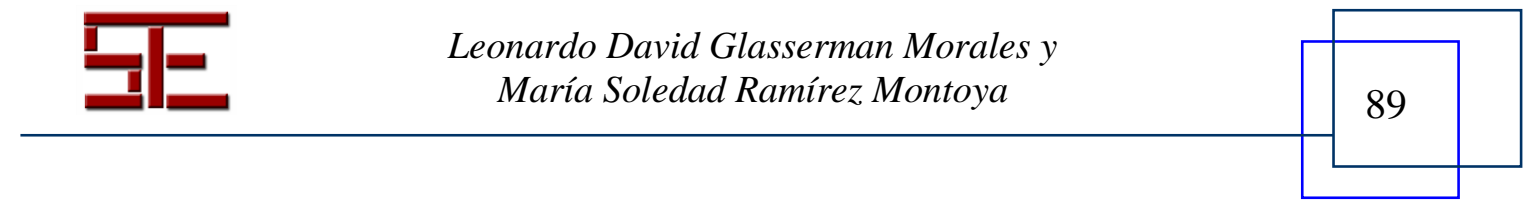




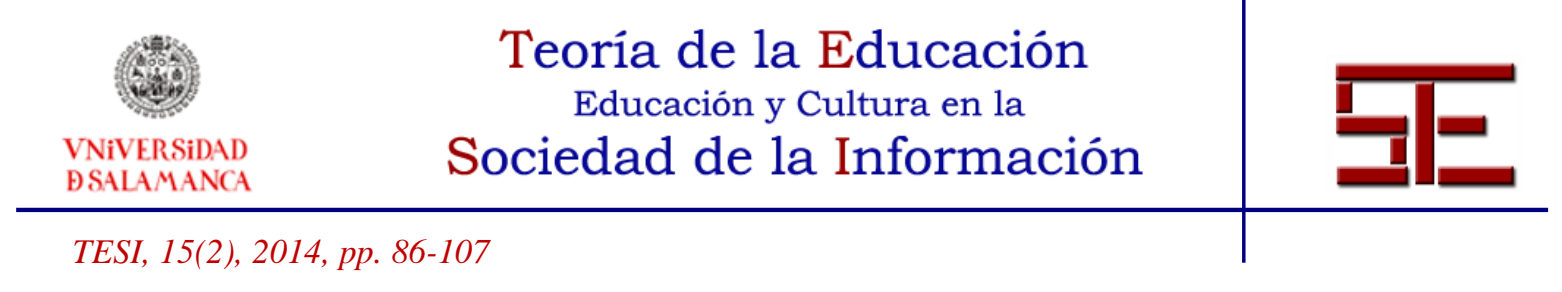

En relación con las limitaciones del estudio, destaca el hecho de que se trabajó en una sola institución educativa delimitada por sus propios horarios escolares y programación de actividades. El tiempo también fue un factor clave y es que en el plan curricular de los grados de primaria se contemplan períodos destinados a evaluaciones como la prueba de logro académico llamada ENLACE, períodos vacacionales, capacitación docente, entre otros.

\section{1.- Planteamiento del problema}

En el ámbito académico el uso de la tecnología ha sido de gran apoyo para llevar a cabo actividades formativas, sin embargo, se sabe que la tecnología requiere un trabajo previo para ser integrado en las tareas educativas. De acuerdo con Valverde, Garrido y Fernández (2010), las buenas prácticas educativas que se apoyan con tecnologías de información y comunicación (TIC) exigen acciones como la comprensión de conceptos y procedimientos de las TIC, el desarrollo de estrategias didácticas de tipo constructivista, conocer las dificultades más comunes de los alumnos y entender cómo las TIC pueden apoyar a superarlas y tener conocimiento previo de la formación de los alumnos. En el mismo sentido, Correa y Martínez (2010) indican que lo importante a la hora de educar no es la tecnología en sí misma, sino la calidad de los procesos de enseñanza-aprendizaje y la coherencia de las actividades curriculares.

Existe un reto palpable a la hora de vincular un buen uso de TIC en el currículo educativo en todos los niveles educativos, pero muy en especial en el nivel de educación básica. Investigaciones como la de Expósito y Manzano (2010) en el nivel de educación primaria dan cuenta del éxito al utilizar correctamente las TIC en el aula, indicando un mejor desempeño en las tareas y en la motivación de los alumnos. Asimismo, Ramírez y Burgos (2011b) coordinaron un libro el cual contiene diferentes investigaciones aplicadas sobre el proyecto denominado "Knowledge hub (KHub-12) para educación básica". Dicho proyecto tuvo por objetivo enriquecer un acervo clasificado e indexado de Recursos Educativos Abiertos de educación básica para México, América Latina y el resto del mundo. Se realizó un trabajo interinstitucional con profesores e investigadores de educación básica, con el fin de apoyar la mejora de los procesos educativos y a la vez contribuir a la reducción de la brecha digital.

En este contexto de experiencias, dentro del proyecto macro apoyado por CUDICONACYT, donde se trabajó con docentes de diversos niveles educativos, surgió el interés por analizar concretamente en los formadores del nivel de educación básica:

\section{¿Cuáles son los retos y oportunidades que tienen los profesores de educación básica al integrar REA y OA en sus procesos formativos para incentivar el aprendizaje activo?}

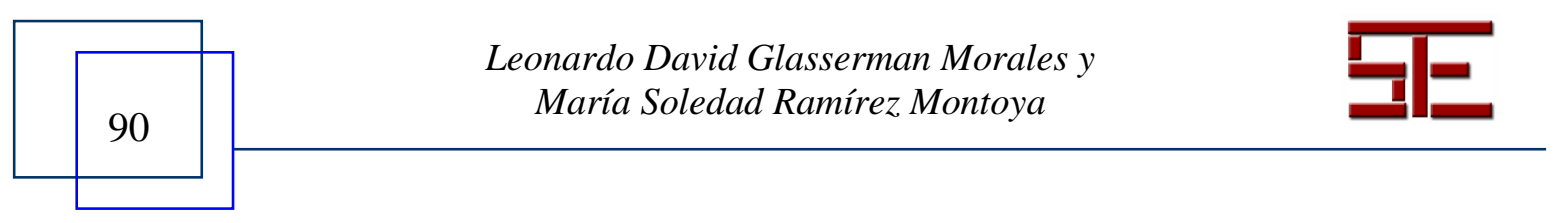




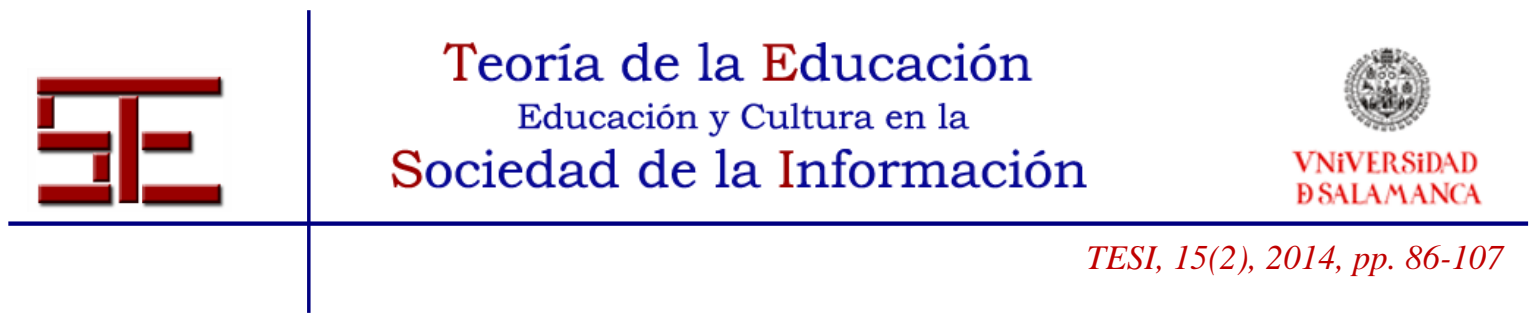

El estudio pretendía realizar un primer acercamiento de la práctica de docentes y alumnos de la institución de nivel primaria hacia el uso de diferentes REA, OA y repositorios educativos. El objetivo era identificar el conocimiento para integrar REA y $\mathrm{OA}$ en los ambientes formativos, los resultados positivos y las áreas de oportunidad para que estos materiales sean de apoyo en la formación de los aprendizajes.

\section{2.- Supuestos de investigación}

Se tenía la idea de que no existía conocimiento por parte de los docentes de educación básica sobre los REA y OA, tampoco de que hubiera una cultura de uso de recursos digitales que no infringieran derechos de autor, por lo que, al término del proyecto, el grupo de alumnos participantes y sus docentes se esperaba que estuvieran familiarizados con el uso de REA, OA, repositorios y catálogos de esos recursos digitales. Así mismo, durante el transcurso del proyecto los participantes podrían desarrollar habilidades y criterios para identificar y seleccionar los REA y OA cuando les fuera requerido.

\section{3.- MARCO CONCEPTUAL}

\section{1- Recursos Educativos Abiertos}

Actualmente incrementar el acceso al conocimiento y oportunidades educativas debe ser una preocupación global. Por ello, D’Antoni (2008) indica que un gran número de iniciativas han motivado la aparición de movimientos de Recursos Educativos Abiertos (REA), los cuales buscan ese cometido a través de compartir contenido educativo. La UNESCO (2002) define a los REA como materiales en formato digital que se ofrecen de manera gratuita y abierta para educadores, estudiantes y autodidactas para su uso y re-uso en la enseñanza, el aprendizaje y la investigación. De esa forma, se tienen recursos digitales de calidad y que pueden ser utilizados y reutilizados en diferentes contextos educativos.

Si bien es cierto que los recursos digitales tienen un fin didáctico, también debiera pensarse en la investigación. De acuerdo con Atkins, Brown y Hammond (2007) los REA son recursos destinados para la enseñanza, el aprendizaje y también la investigación que residen en el dominio público o que han sido liberados bajo un esquema de licenciamiento que protege la propiedad intelectual y permite su uso de forma pública y gratuita o permite la generación de obras derivadas por otros. Los REA se identifican como cursos completos, materiales de cursos, módulos, libros, video, exámenes, software y cualquier otra herramienta, materiales o técnicas empleadas para dar soporte al acceso de conocimiento. Por su parte, Downes (2007) indica el modelo abierto denominado 4R, las cuales se refieren a lo que formalmente se puede hacer con

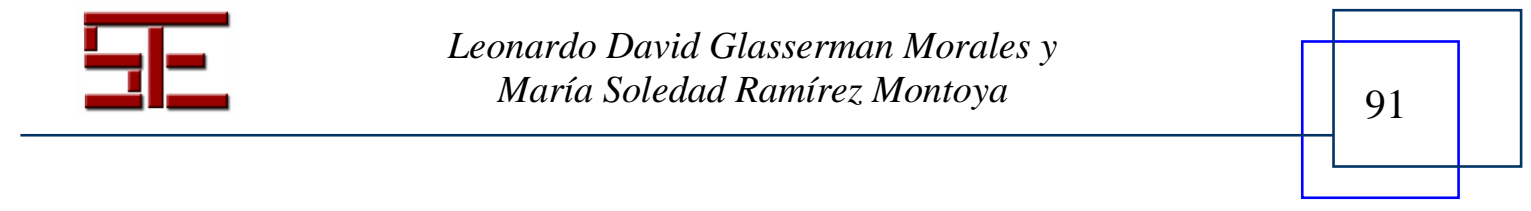




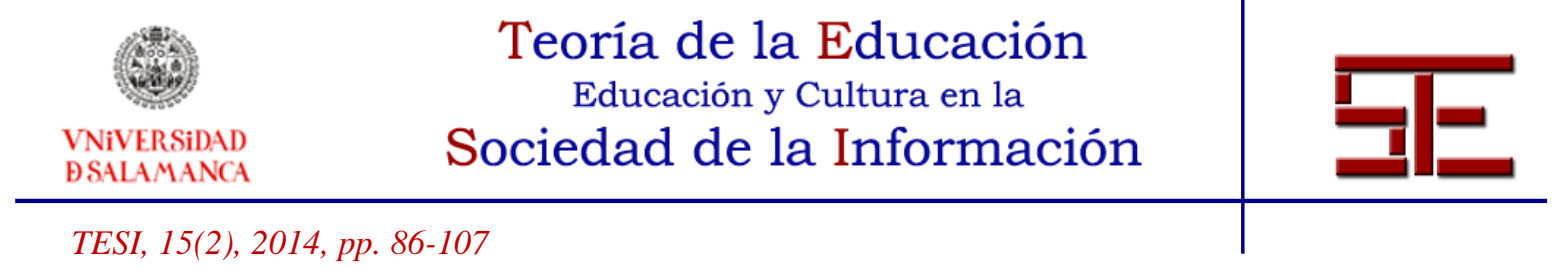

la licencia de los REA. Las 4R significan: reusar, redistribuir, revisar y remezclar. Por lo tanto, los REA tienen impacto en la enseñanza, aprendizaje e investigación mediante su uso, reuso y distribución, logrando así diseminar el conocimiento.

Es importante considerar que los REA tengan aplicación con los diferentes modelos y estrategias de enseñanza utilizados en los nuevos contextos de enseñanza-aprendizaje. De acuerdo con Ávila (2008) los REA deben conducir a establecer alianzas institucionales para aprovechar las similitudes culturales y de enfoques, y de igual forma para incorporar elementos que reduzcan las diferencias, ampliar las perspectivas e introducir innovaciones que permitan potenciar los resultados e intentar aplicaciones educativas de la tecnología. Por lo tanto, queda de manifiesto que los REA pueden insertarse en nuevos ambientes de aprendizaje y serán los docentes quienes les pueden dar un enfoque con base en su práctica docente.

Asimismo, resulta interesante integrar los REA a la planeación educativa de los docentes con la intención de aprovechar recursos que ya han sido diseñados. De acuerdo con la OPAL (2011) existen acciones conocidas como Prácticas Educativas Abiertas (PEA), las cuales se refieren a un conjunto de actividades en torno al diseño instruccional y su aplicación en actividades enfocadas al desarrollo de aprendizaje a través de REA. Para ello, se espera la creación, uso y reuso de REA y la adaptación del mismo en un contexto específico.

Si bien es cierto que existen diferentes movimientos encaminados hacia las prácticas abiertas, aún prevalece la proliferación de contenidos, siendo pocas las instituciones que desean no solo publicar sino reutilizar el contenido de REA ofrecido bajo licencias abiertas (DeVries, 2013). A continuación se presenta el tema de objetos de aprendizaje.

\section{2.- Objetos de Aprendizaje para incentivar el aprendizaje activo}

El aprendizaje autodirigido muchas veces requiere de herramientas que permitan evaluar antes, durante y después de someterse a un nuevo aprendizaje, es por ello la importancia de los Objetos de Aprendizaje (OA). De acuerdo con Enríquez (2004) el término se refiere a los recursos digitales que apoyan la educación y pueden reutilizarse constantemente, indicando las características de una mínima estructura como el objetivo, la actividad de aprendizaje y el sistema de evaluación. Por su parte, Wiley (2000) indica que la idea fundamental de un OA es la de construir componentes curriculares para ser reutilizados varias veces en diferentes ambientes y contextos de aprendizaje. Por tanto, al considerar un OA, tres aspectos deben estar presentes: debe tratarse de un recurso digital, con la posibilidad de ser reutilizado para construir aprendizaje a través de pruebas iniciales, contener actividades de reforzamiento y de evaluación final. Hay áreas más factibles de ser aprendidas mediante OA. Con base en el estudio de Kay y Knaack (2008) se identificó que los estudiantes con más habilidades

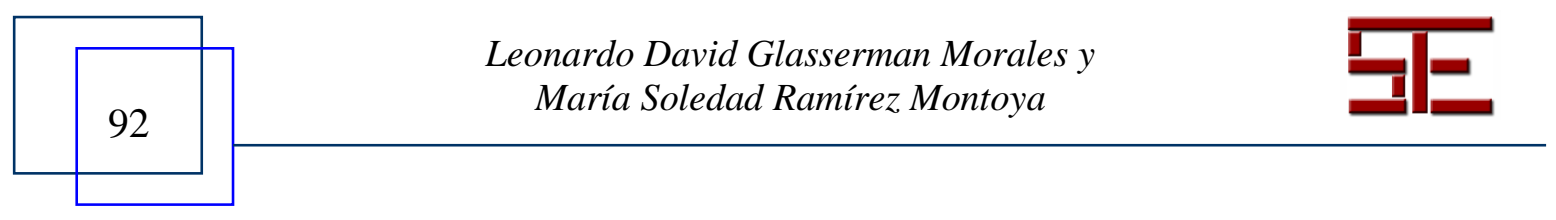




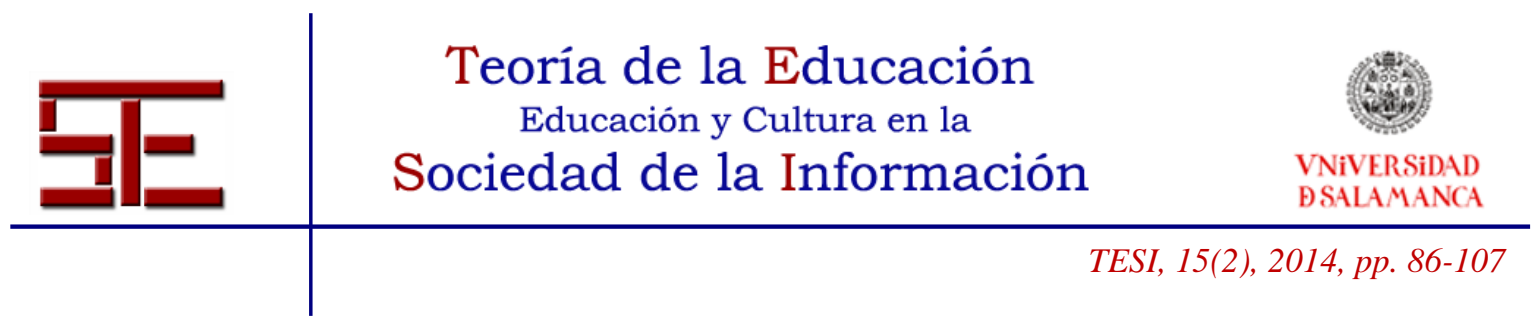

computacionales aprecian mejor los objetos de aprendizaje.

Aprender en los nuevos ambientes de aprendizaje requiere adaptar la instrucción a las necesidades y condiciones que se reclaman para el aprendizaje. Por ello, Ramírez (2013) menciona que los modelos y estrategias de enseñanza deben adaptarse a situaciones como el autoaprendizaje, el manejo y uso de información, al uso de las TIC, así como a considerar la conciencia social para el crecimiento colectivo. En ese sentido, pensar en actividades de corte activo es un aliciente para las nuevas generaciones educativas que son más adeptas al uso de TIC.

El aprendizaje activo tiene como fundamento el trabajo colaborativo y la socialización del conocimiento. En palabras de Glasserman (2013) se conceptualiza como un modelo basado en el paradigma sociocultural y cognitivo, el cual está informado por el paradigma sociocultural por el hecho de que el conocimiento se construye socialmente en una conversación entre alumno-alumno y alumno-docente. Por otra parte, se nutre del paradigma cognitivo al indicar que el conocimiento es asimilado en diferentes estructuras mentales de acuerdo con la teoría de desarrollo psicogénico. En el modelo se utilizan estrategias y técnicas, como el aprendizaje por descubrimiento y el reforzamiento positivo, respectivamente. El ambiente de aprendizaje juega un papel importante y busca fomentar un rol colaborativo de acuerdo con la propuesta de Dillenbourg (1999). Con el aprendizaje activo se busca potencializar el aprendizaje autorregulado y la responsabilidad de tareas.

De acuerdo con Koopmann (2002) los participantes deben atravesar las siguientes cuatro etapas en el proceso de aprendizaje activo: a) Observación y reflexión: Revisar, cuestionar e integrar la información producto de la experiencia, b) Formación de conceptos y reflexiones: Aprender creando teorías lógicas, c) Experimentación activa: Aplicar los conceptos en nuevas situaciones o toma de decisiones, d) Experiencia concreta: Involucrarse en nuevas experiencias.

El siguiente tema presenta los repositorios donde se alojan los recursos educativos abiertos y objetos de aprendizaje.

\section{3.- Repositorios de los recursos educativos abiertos y objetos de aprendizaje}

Generalmente las instituciones de educación no ofertan su producción científica de forma abierta al público, aunque recientemente han tomado fuerza en diferentes regiones del mundo políticas públicas con respecto al acceso abierto. La idea principal es que todos los resultados de proyectos financiados deben darse a conocer de manera abierta y para ello se requiere de repositorios. De acuerdo con Heery y Anderson (2005) un repositorio es un proveedor de datos y de forma genérica se puede definir como un lugar central donde se registran datos para su almacenamiento y conservación con

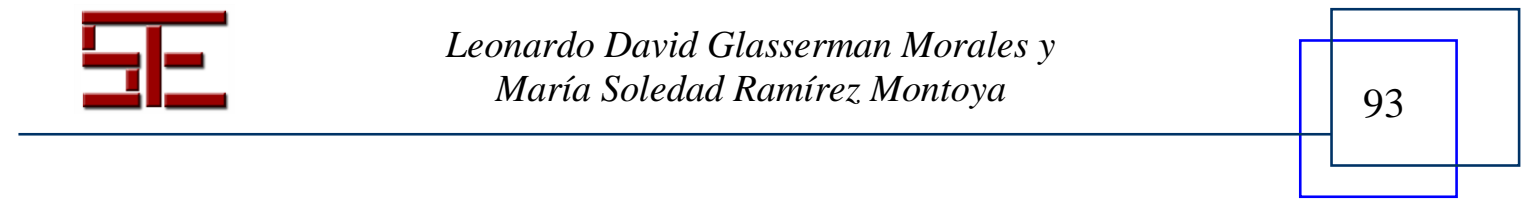




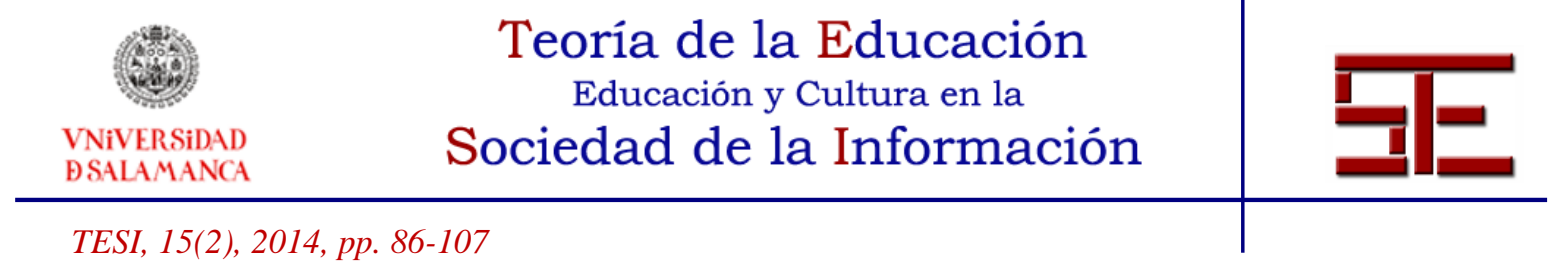

propósitos diversos de seguridad o consulta posterior. Pagés-Arévalo y Lezcano (2011) hacen referencia a la existencia de repositorios de objetos de aprendizaje (Learning Objetcs Repositories, LOR por sus siglas en inglés), los cuales son colecciones digitales de recursos educativos o metadatos enfocados a facilitar el reuso de materiales en todo el mundo.

En el caso de México, se han desarrollado diferentes proyectos de repositorios institucionales abiertos. Mortera (2011) indica algunos ejemplos de repositorios como el Centro de Recursos para la Enseñanza y el Aprendizaje (CREA) desarrollado por la Universidad de Guadalajara, el cual está orientado al fortalecimiento del proceso de enseñanza-aprendizaje y a la formación integral de los estudiantes de nivel superior y medio superior mediante el almacenamiento de Objetos de Aprendizaje (OA). El programa DAR (Desarrolla, Aprende y Reutiliza) es una iniciativa del Tecnológico de Monterrey que aborda los desafíos inherentes de la formación de investigadores educativos. Busca apoyar la enseñanza e investigación mediante la creación de acceso a una colección creciente de acceso abierto de recursos y materiales digitales producidos y desarrollados por la comunidad académica. Así mismo, el Laboratorio M-Learning del Instituto Tecnológico de Chihuahua explora la aplicación y uso de dispositivos móviles en el ámbito educativo, con especial énfasis en el uso de secuencias de aprendizaje y desarrollo de podcasts multimedia con narrativas digitales para evidenciar el aprendizaje y competencias.

Existen otros sitios que no precisamente son repositorios, sino catálogos que indexan recursos de otros sitios. Un ejemplo de este tipo de catálogo es TEMOA (2011), el cual es un distribuidor de conocimiento que facilita un catálogo público y multilingüe de colecciones de REA, que busca apoyar a la comunidad educativa a encontrar aquellos recursos y materiales que satisfagan sus necesidades de enseñanza y aprendizaje, a través de un sistema colaborativo de búsqueda especializado y herramientas sociales.

\section{4.- Investigaciones relacionadas}

Algunas investigaciones relacionadas se enuncian a continuación. Ramírez y Burgos (2010) presentaron una compilación de casos de estudio utilizando recursos educativos abiertos, en su libro también en formato abierto. Ahora bien, Valenzuela y Ramírez (2010) investigaron el proceso de adopción de las competencias requeridas por los docentes en la sociedad del conocimiento y desarrollaron Objetos de Aprendizaje Abiertos. En tanto, Celaya, Lozano y Ramírez (2009) describieron el proceso de apropiación tecnológica en profesores que incorporan recursos educativos abiertos en educación media superior.

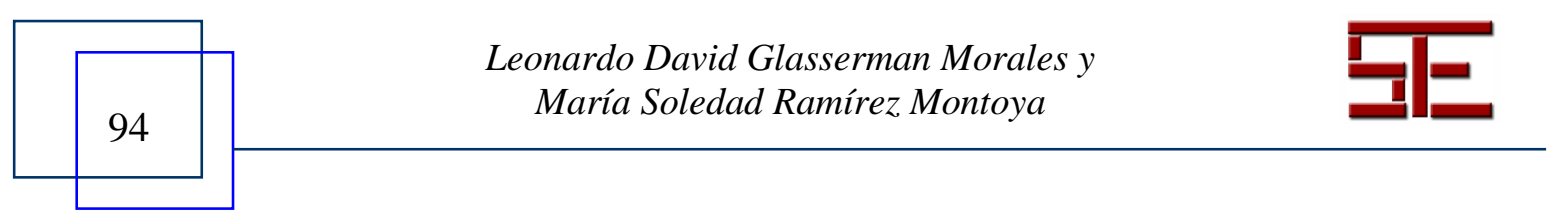




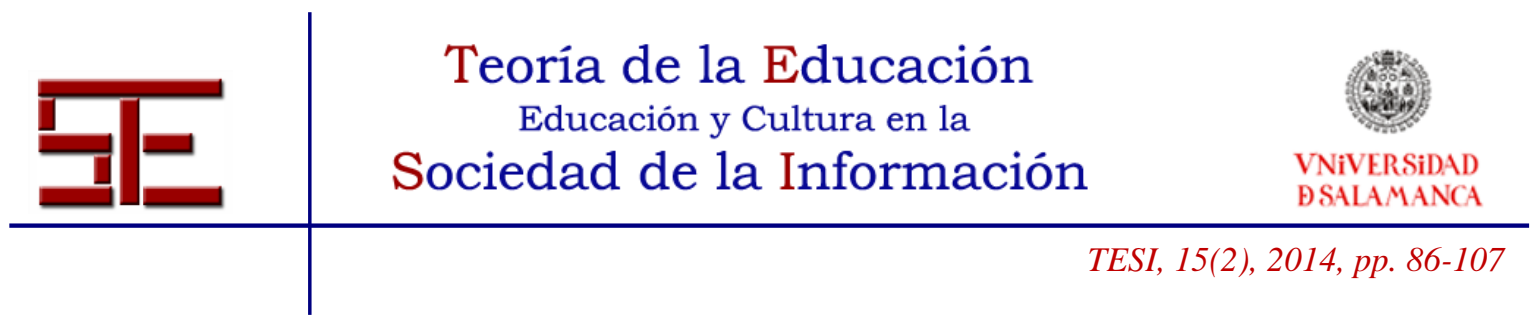

Por su parte, Glasserman, Ramírez y Juárez (2013) documentaron dos redes virtuales, una regional en México y otra internacional en diferentes países de Latinoamérica, las cuales fomentan prácticas educativas abiertas. De igual forma, Glasserman (2012) indicó en su estudio los beneficios de trabajar con un diseño de prácticas educativas abiertas donde se utilicen REA para la enseñanza-aprendizaje. En la misma línea, Sabiha (2012) realizó un estudio donde enfatiza que los docentes generalmente utilizan recursos de Internet para preparar el contenido y materiales del curso, sin embargo, no tienen conocimiento sobre Objetos de Aprendizaje ni de repositorios, por lo que concluyó que los repositorios no eran utilizados como una fuente de búsqueda para la preparación de contenido docente. A su vez, Ramírez y Burgos (2011a) realizaron un estado del arte sobre las prácticas abiertas en Latinoamérica e indicaron recomendaciones tales como promover una nueva cultura de prácticas educativas para adquirir habilidades necesarias para hacer un buen uso de los REA como alfabetización digital e informacional, así como promover una comunidad abierta donde se compartan las mejores prácticas educativas.

\section{4.- METODOLOGÍA}

El estudio se trabajó con el método cualitativo para dar una comprensión al fenómeno a través del estudio de casos. La investigación basada en el estudio de casos involucra el estudio de un aspecto explorado a través de uno o más casos dentro de un sistema cerrado (Creswell, 2007). Por su parte, Stake (1995) indicó que el estudio de casos puede ser intrínseco, instrumental o múltiple. De acuerdo con Yin (2003) se recomiendan seis tipos de información para recolectar en un estudio de casos como documentos, registros de archivos, entrevistas, observaciones directas, observación participante y artefactos físicos. Para efectos de este estudio, se propuso una metodología del estudio de casos múltiples (con tres casos), de corte descriptivo (para analizar los usos y resultados de la integración de REA y OA), con el fin de identificar, a través de la observación directa de los investigadores, el conocimiento para integrar REA y OA en los ambientes formativos, los resultados positivos y las áreas de oportunidad para que estos materiales sean de apoyo en la formación de los aprendizajes.

\section{1.- Participantes}

La intención para desarrollar la investigación involucraba a tres diferentes instituciones de educación primaria en la zona metropolitana de Monterrey (localidades de García y Santa Catarina) del sector público y privado; a través del director de la zona escolar $\mathrm{n}^{\circ} 2$ del Estado de Nuevo León, México. Se realizó una sesión para la presentación del proyecto y las instituciones decidieron evaluar si participarían o no en el proyecto. Fue

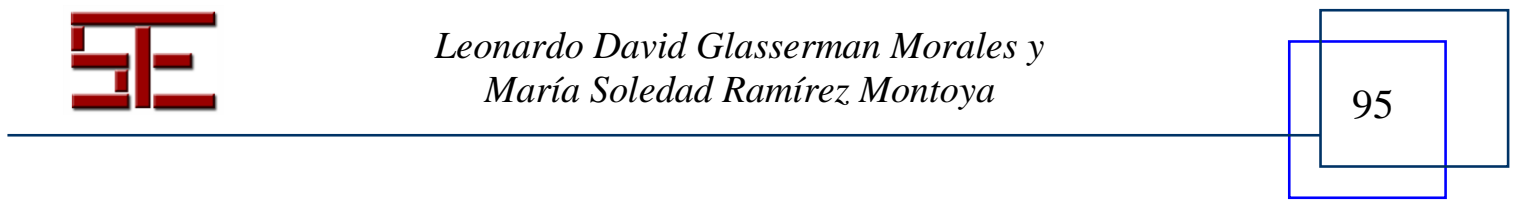




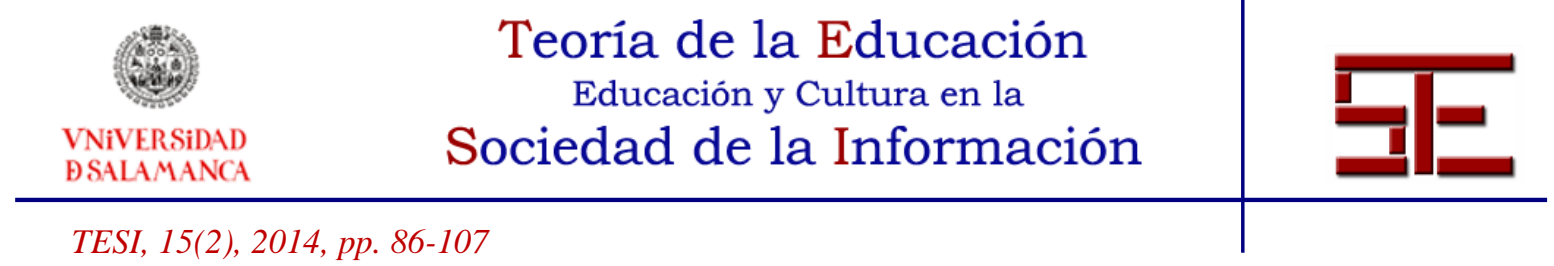

así como la escuela primaria "15 de Mayo" decidió conocer las ventajas del proyecto y aceptó participar con tres grupos de aproximadamente 50 alumnos cada uno. Las demás instituciones educativas decidieron no participar en el proyecto. Por lo tanto, se siguió un muestreo no probabilístico por conveniencia (Creswell, 2008), debido a que se contaba con voluntarios para participar en el estudio en grupos ya asignados previamente. Para efectos de identificación, los grupos que participaron se catalogaron por casos mediante la siguiente nomenclatura: Caso A, Caso B y Caso C.

\section{2.-Situación educativa}

El repositorio que se desarrolló en el macroproyecto de esta investigación se denomina Educonector, el cual facilita un buscador que integra mecanismos de filtrado de información, y se define como un agregador de información del tipo infomediario (Educonector. info, 2014). Un infomediario es un sitio web que reúne y organiza grandes cantidades de datos e información (metadatos) y actúa como intermediario entre las personas que buscan información y las entidades que proveen la información (repositorios institucionales y temáticos) (ver imagen 1).

El objetivo principal de Educonector info es ayudar a dar visibilidad a la producción científica, académica y documental de las instituciones de educación superior, centros de información, bibliotecas, centros de innovación e investigación y otras fuentes de producción intelectual. Esto por medio de la interconexión de repositorios institucionales con contenido digital para facilitar la tarea de encontrar, evaluar y compartir Recursos Educativos Abiertos (REA) y Objetos de Aprendizaje (OA) con la comunidad de habla hispana (Educonector.info, 2014).

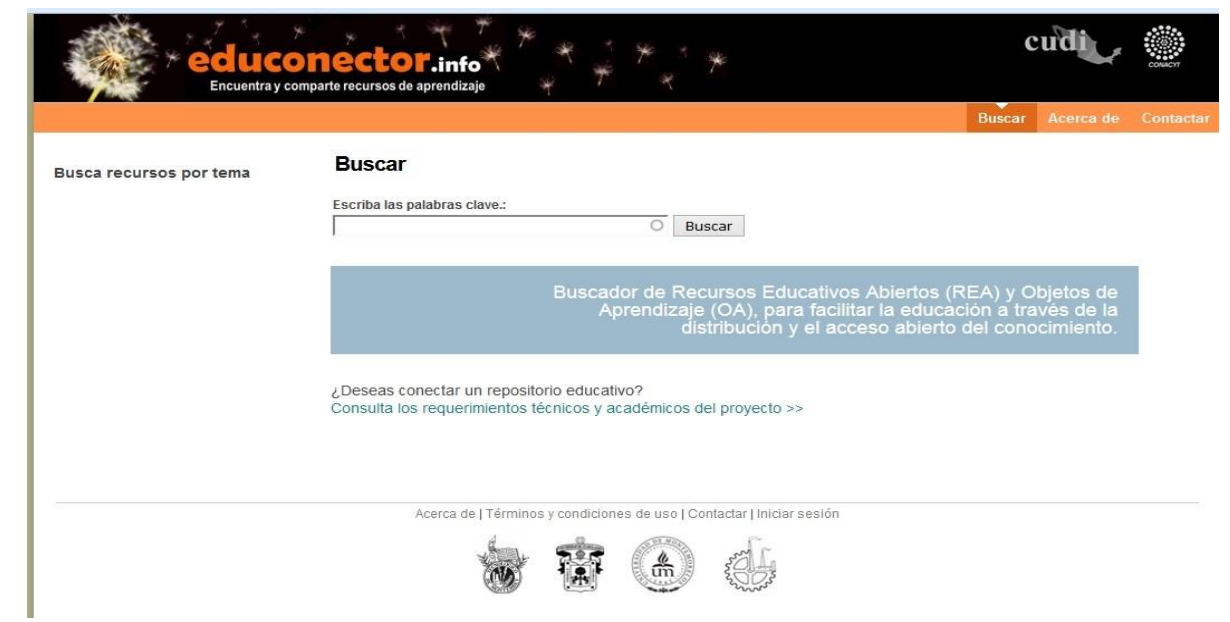

Imagen 1. Portal del repositorio Educonector.info.

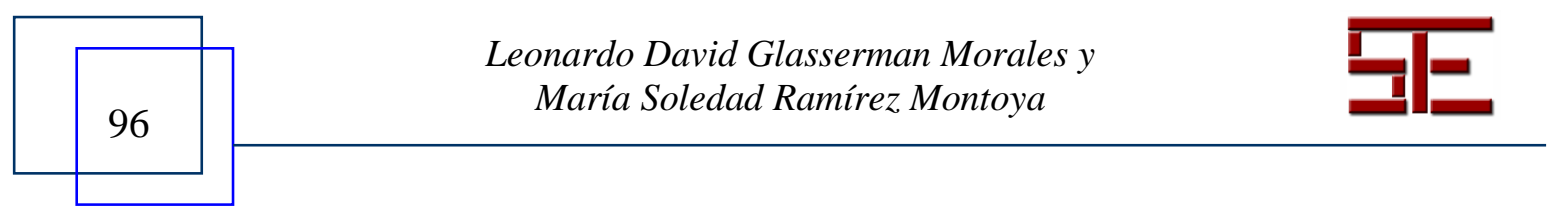




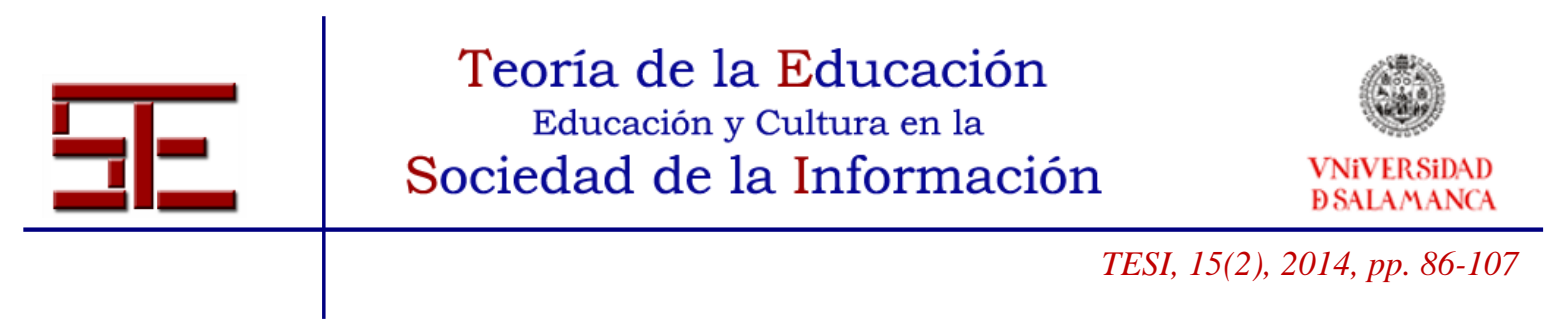

Con base en lo anterior, el equipo de investigación dio a conocer a los docentes participantes en el estudio el metaconector para que pudieran seleccionar sus recursos de tal forma que existiera una reducción en el tiempo de búsqueda en lugar que si lo hicieran en cada uno de los repositorios y catálogos de las instituciones que participaban en el proyecto (CREA, DAR, laboratorio mlearning, TEMOA). Así fue como los docentes de los tres grados eligieron los recursos digitales que se adecuaban a su planeación docente y que pensaban que mejorarían la experiencia en el aprendizaje. Cabe destacar que la valoración del aprendizaje activo en los alumnos se revisó con base en la propuesta de Koopmann (2002).

\section{3.- Unidad de análisis}

Según Spirer (1980) se sugiere que para definir la unidad de análisis el investigador identifique lo siguiente: a) descripción de los límites de la investigación; b) preguntas que se realizarán; c) posibles unidades de análisis; d) unidad de análisis más óptima; e) justificación de elección de unidad; f) preguntarse si la unidad elegida brindará la información necesaria. De acuerdo con lo anterior, las unidades de análisis corresponden a los docentes que participaron en el proyecto y de quienes se desea conocer la experiencia tras el uso de REA y OA como materiales didácticos, a través de sus prácticas formativas en el aula.

\section{4- Técnicas de recolección de datos}

Las técnicas de recogida de información fueron la observación directa en el aula, diario del investigador y del análisis de documentos. La observación directa en el aula permitió verificar el dominio de conocimiento de los docentes en el aula, la aplicación de recursos digitales abiertos (REA y OA) para apoyar su práctica educativa, así como la participación de los alumnos en el aula con base en el aprendizaje activo. Por su parte, el diario del investigador integró datos relacionados con la práctica docente, desempeño docente, aprendizaje activo en el aula e identificación de contexto propicio con recursos tecnológicos. En tanto, el análisis de documentos permitió conocer planeación de actividades que integraran actividades que propiciaban el aprendizaje activo de los alumnos. Una vez que se tenía la información se utilizó una estrategia de interpretación directa con base en la propuesta de Stake (1995) sobre la revisión de asertos y su interpretación conforme se van obteniendo datos.

\section{5.- Validación de datos}

Generalmente, se suele asumir que una investigación es valiosa o aceptable en la medida que es rigurosa, lo que, entre otras cosas, significa que es fiable, válida y generalizable (Sutton y Barry, 1995). Partiendo de estas aseveraciones, la metodología

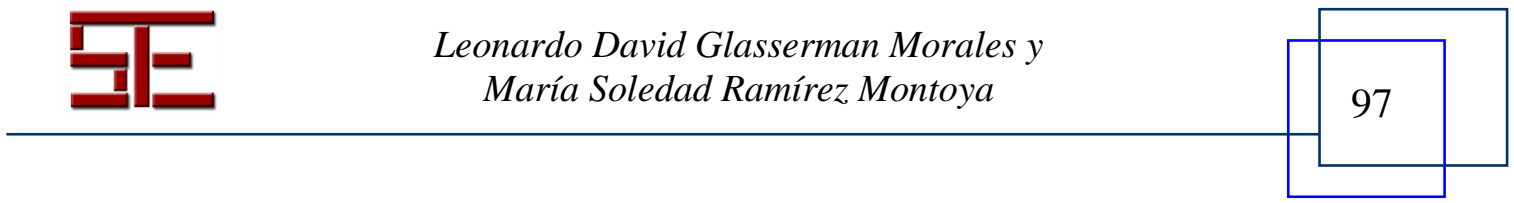




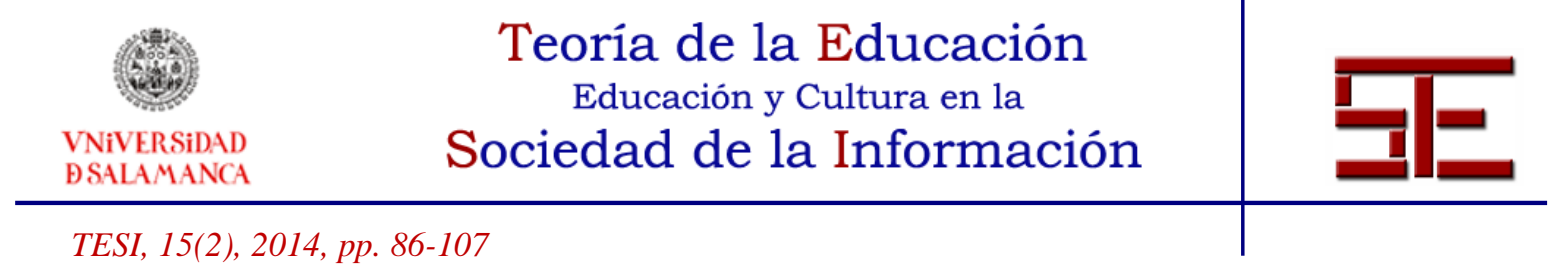

de estudio de casos ha recibido una crítica importante, sobre todo, relacionada con el papel del investigador en términos de sesgo. Así como existen fuertes críticas, existen justificaciones. Numagami (1998) ha fijado algunos criterios o aspectos que se utilizan comúnmente para establecer la calidad del estudio cualitativo. Estos criterios están representados por la validez de modelo o de constructo, la validez interna, la validez externa, la fiabilidad y la triangulación (Yin, 2003), mismos que se utilizarán para validar la presente investigación, a través de la aplicación de la observación de la integración de REA y OA en las clases de tres grupos de educación básica.

\section{5.- RESULTADOS A TRAVÉS DE LOS CASOS}

\section{1- Caso A: Grupo sexto grado}

La profesora del sexto grado de la escuela primaria "15 de Mayo" se apoyó en el uso de REA en forma de video para poder reforzar temas de las características de países de Asia. El primer grupo constaba de nueve alumnos (cinco hombres y cuatro mujeres de entre diez y once años) y presentaron información de India. Se habló acerca de la bandera del país, la vestimenta, la cultura, las principales tradiciones y religión. Al final de la presentación, una de las alumnas realizó preguntas al grupo sobre características generales de la vestimenta y alimentación. La profesora complementó la información expuesta por los alumnos a través de un recurso digital sobre los monumentos históricos acerca de la India.

Se observó que la profesora tenía conocimientos previos sobre el uso de las TIC, para manipular el cañón y otros dispositivos como la computadora personal y manejo de navegadores. El recurso digital se obtuvo de un blog en donde el video insertado pertenecía al proveedor de contenido Slideshare. Cabe mencionar que se realizó la búsqueda del recurso desde el repositorio Educonector.info, pero no se encontró información directamente. Se identificó que algunos recursos se encontraban en el sitio de Slideshare, por lo cual se realizó una búsqueda y a través de un blog se logró obtener el recurso (video) que se utilizó. El recurso contenía imágenes de monumentos importantes como el palacio real, un monumento a los caídos en Afganistán, la puerta del presidente de la India, la residencia oficial del presidente de Delhi. A través del recurso se hizo referencia a los monumentos y los alumnos interactuaron reconociendo personajes importantes, por ejemplo, a Mahatma Gandhi. Así mismo, el recurso sirvió para presentar el monumento reconocido "Taj Mahal” y se explicó la historia de por qué se construyó ese monumento. El recurso utilizado contenía las características que de acuerdo con Enríquez (2004) debían tener los recursos digitales que se utilizan en la educación, en este caso el objetivo y estructura que el docente aprovechó para apoyar la exposición de contenidos.

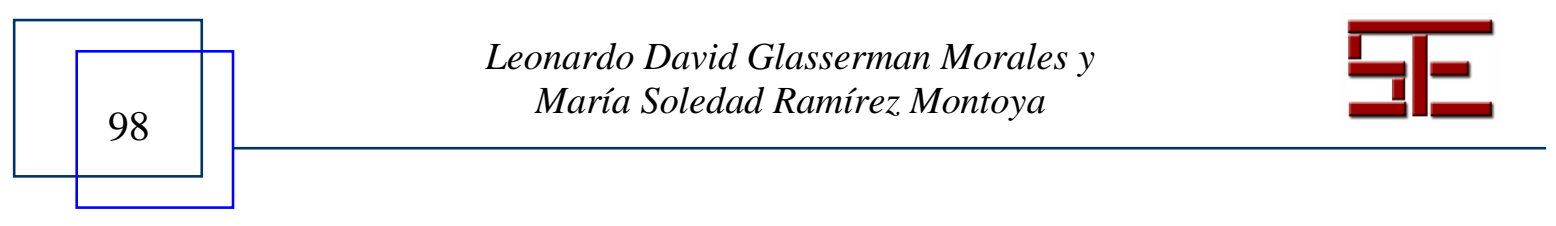




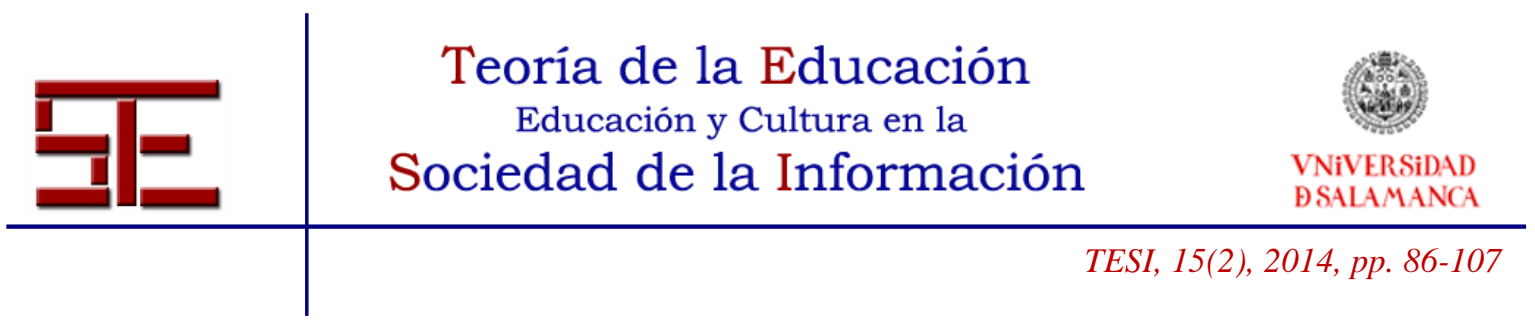

El segundo equipo, formado por nueve alumnos (cinco hombres y cuatro mujeres), presentó el tema de China. Los alumnos estuvieron vestidos con prendas tradicionales del país. Entre los temas que se mostraron estuvieron la vestimenta (emperador y gobernante chinos), actividades principales, información política, geográfica, principales monumentos (muralla china), cultura (dragones) y la comida. El segundo recurso digital utilizado por la profesora para reforzar el tema de China se obtuvo de un blog. Se trató de una presentación obtenida a través de SlideShare la cual incluyó imágenes de China acompañadas de música instrumental.

\section{2- Caso B: Grupo quinto grado}

La profesora del grupo se apoyó en Internet para poder presentar el tema de prevenciones al cocinar alimentos. Debido a que realizó una búsqueda en el repositorio, la profesora mencionó que los recursos contenían temas muy elevados para el nivel primaria, por lo que no pudo seleccionar un recurso de esas fuentes que se le habían presentado previamente. Esto se constituyó en una limitante en el uso del repositorio propuesto. A pesar de iniciativas como el llamado proyecto Knowledge Hub (ahora TEMOA), Ramírez y Burgos (2011b), con contenidos enfocados a la educación básica, parecen ser insuficientes cuando se realiza la búsqueda de contenidos específicos como lo fue el presente caso.

El grupo de alumnos (integrado por 26 personas) realizaba anotaciones en sus cuadernos sobre la presentación del tema. Todo el grupo estuvo atento mientras la profesora exponía el tema apoyándose en información del libro de texto, así como en un video. Desafortunadamente, el equipo del aula tuvo problemas tecnológicos ya que el regulador se quemó y el proyector se apagaba constantemente. Esta limitante reafirma lo que exponen Correa y Martínez (2010) acerca de que lo importante en el proceso educativo no es la tecnología en sí misma, sino la calidad de los procesos de enseñanzaaprendizaje y la coherencia de las actividades curriculares. El uso del recurso permitió que los alumnos interactuaran con la maestra, algunos alumnos realizaban preguntas y se apoyaban respondiendo entre ellos. Como recurso adicional al tema, la profesora se apoyó en Youtube para realizar la presentación de un video titulado "La dieta correcta". Cuando se presentó el video, todos los alumnos pusieron atención. El recurso sirvió para recordar elementos que ya se habían revisado en clase, en este caso, no se utilizó ningún REA ni OA para exponer los contenidos, sino para reafirmar algo previamente expuesto con un recurso tradicional como el libro de texto.

La profesora invitó a los alumnos a participar y compartir con sus compañeros un menú de comida de un restaurante. Una alumna presentó su menú. Con la información del recurso (video) y lo que se había revisado la profesora realizó un ejercicio práctico e

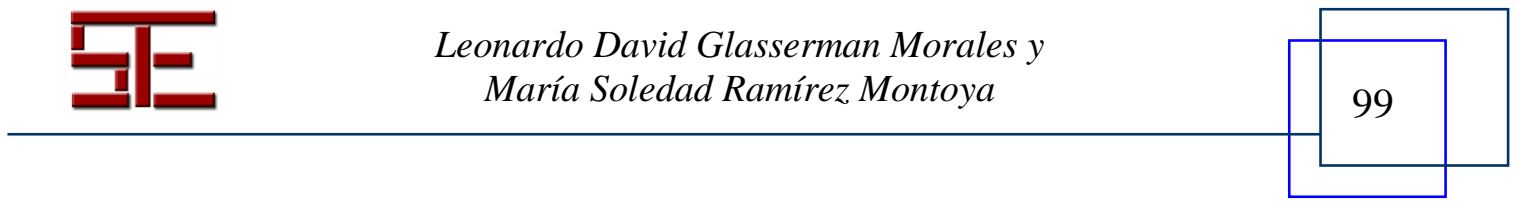




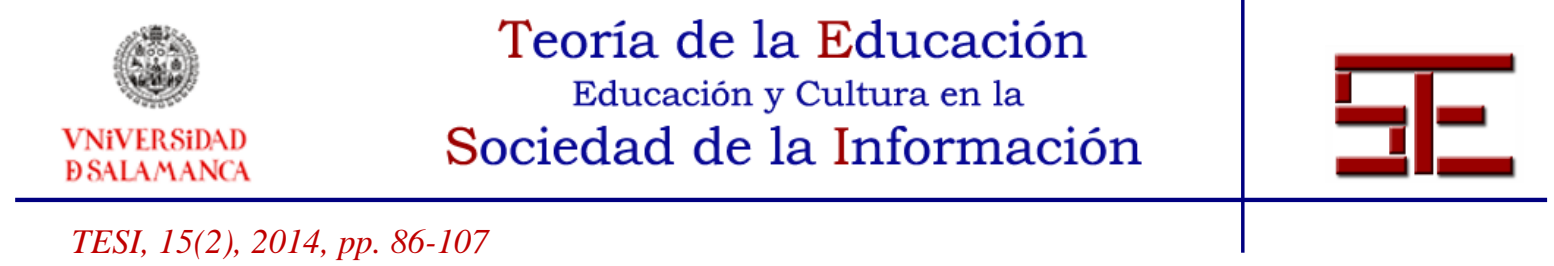

invitó a sus alumnos a que participaran en la elaboración de un menú balanceado para un niño de tres años. Algunas respuestas fueron "cereal con vaso de leche en el desayuno". Se fomentó el trabajo en equipo (en grupos de cuatro personas), para realizar la actividad de un menú balanceado de acuerdo con diferentes perfiles: niño de tres años, mujer embarazada, joven que hace ejercicio. Así los alumnos lograron desarrollar la actividad al apoyarse en el libro de ciencias y en los ejercicios realizados previamente.

\section{3- Caso C: Grupo primer grado}

El grupo estaba integrado por 26 alumnos. En el aula se contaba con cañón que enviaba la imagen hacia una pared que hacía la función de proyector. Se utilizó una computadora personal, Internet y bocinas externas. Previamente, la maestra había seleccionado un REA sobre el uso de las horas del reloj. Algunos tipos de relojes que se revisaron fueron el de agua, el de arena, de cera, los relojes mecánicos (de bolsillo, de péndulo, analógico de pared). La profesora presentaba el tipo de reloj y los niños los asociaban de acuerdo con su experiencia. Por ejemplo: el reloj digital "es el que te despierta".

Los niños se mostraron inquietos por la sombra del proyector hacia la pared. Aunque todos participaron activamente. La profesora realizó una actividad con el recurso obtenido de TEMOA para identificar diferentes horas en el reloj y asociarlas con la indicación en número de las letras.

En la siguiente tabla se presentan a manera de resumen los resultados obtenidos en los tres casos de estudio.

Tabla 1

Principales resultados obtenidos en los tres casos de estudio

Caso Principales resultados

\section{Tecnológicos Didácticos}

A Uso de REA para presentar tema de clase Observación y reflexión, por parte de los alumnos (Presentación de formación de conceptos y diferentes culturas del mundo). Uso de reflexiones, experimentación herramientas tecnológicas en el aula por activa, experiencia concreta. parte de la docente. Conocimiento de software con licenciamiento abierto por

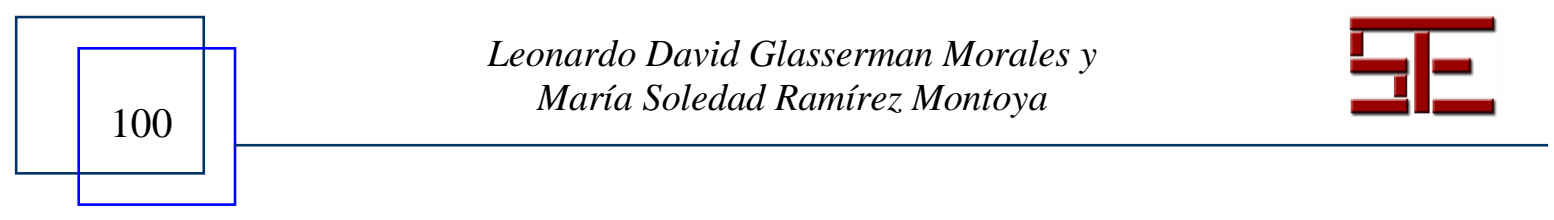




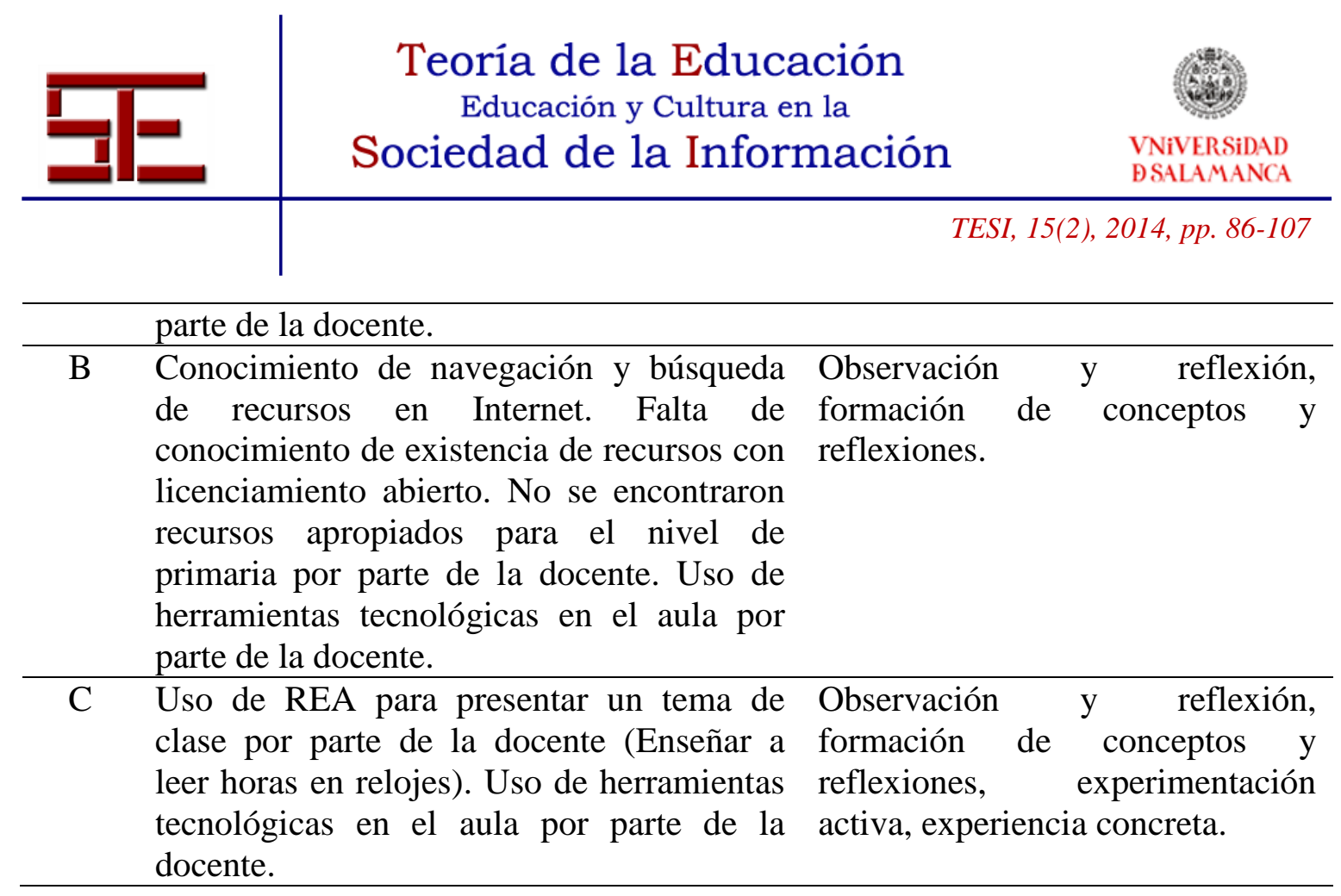

\section{6.- DISCUSIÓN}

A continuación se presenta la discusión identificada en cada uno de los casos analizados.

Los docentes tienen poco o nulo conocimiento para identificar e integrar REA y OA en sus ambientes formativos. Se identificó que los docentes conocen los recursos y saben cómo integrarlos a su planeación docente, sin embargo, no tienen conocimiento de dónde buscar recursos para ser reutilizados. De acuerdo con Sabiha (2012) es Internet el proveedor de recursos que más utilizan los docentes para preparar sus materiales, careciendo de conocimiento acerca de Objetos de Aprendizaje y repositorios. Por lo tanto, existe un área de oportunidad en los docentes para dar a conocer fuentes como repositorios y catálogos con recursos abiertos.

Asimismo, los docentes no tienen conocimiento acerca del licenciamiento que existe en los recursos que utilizan en el aula y usan indiscriminadamente recursos con registro y recursos libres. Se encontró que los docentes que participaron en el estudio recurrían a Internet para encontrar recursos digitales de apoyo para su práctica docente cuando no encontraban lo que buscaban en los repositorios que se les indicaron. Es importante considerar que existen sitios dedicados a almacenar recursos con licenciamiento abierto tal y como lo mencionan Pagés-Arévalo y Lezcano (2011) al indicar que los repositorios de objetos de aprendizaje (LOR por sus siglas en inglés) son colecciones digitales de recursos educativos o metadatos enfocados a facilitar el reuso de materiales en todo el mundo. Por lo tanto, es prioritario que los docentes conozcan las diferentes clasificaciones de licenciamiento de los recursos para que puedan elegir

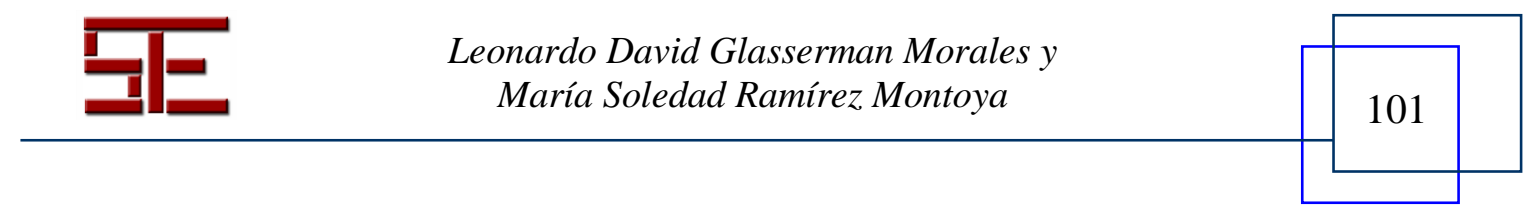




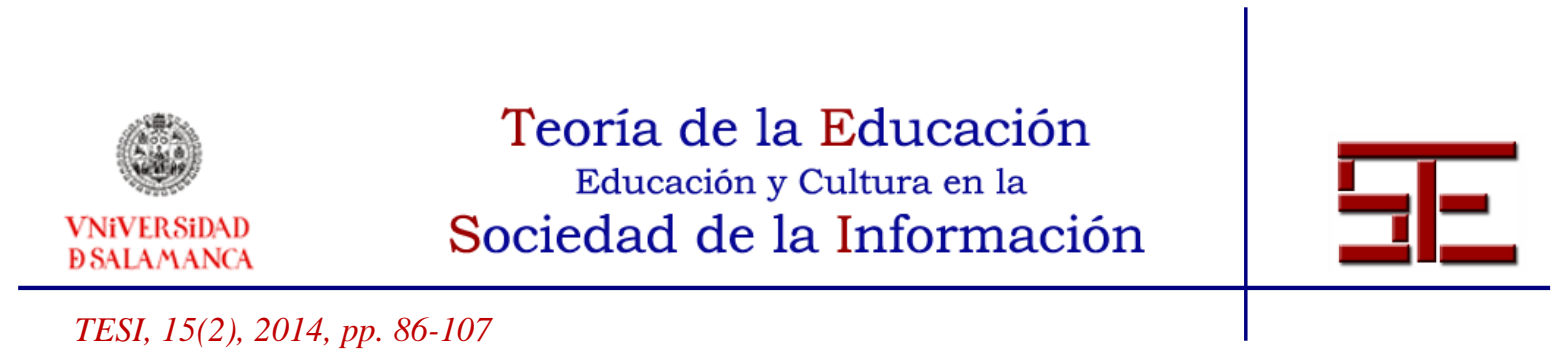

aquellos que estén distribuidos de forma abierta para respetar los derechos de autor de aquellos que sí tienen registro.

Con respecto al aprendizaje activo, se espera que todo recurso digital que se utilice deba fomentar la práctica del aprendizaje activo. En ese sentido, se identificó que los recursos utilizados priorizan primero un aprendizaje individual para posteriormente llegar a la socialización del conocimiento. En el entendido que Glasserman (2013) describe el aprendizaje activo como un modelo en donde el conocimiento se construye socialmente en una conversación entre alumno-alumno el alumno-docente. Por lo tanto, los REA utilizados en el estudio caben dentro de la categoría de fomentar un aprendizaje activo en el contexto en el que se utilizaron.

Los recursos digitales que se utilizaron sirven para fomentar el trabajo colaborativo. Con base en los registros de observación se identificó que los REA utilizados, así como otros recursos digitales, contribuyeron en el trabajo colaborativo al incluir grupos de trabajo, la participación socializada. De acuerdo con Dillenbourg (1999) la participación colaborativa y cooperativa se desarrolla en grupos de trabajo pequeños en donde el ambiente de aprendizaje juega un papel importante. El uso de REA fomentó un trabajo colaborativo tal y como se percibió en los grupos de sexto grado, donde se presentaron temas de historia y geografía.

Con respecto a las áreas de oportunidad de los materiales utilizados se identificaron pocos recursos para el nivel educativo de primaria. De hecho, este fue un factor muy importante en el estudio ya que se percibió que los docentes primero estaban muy motivados en seleccionar recursos digitales, pero, al momento de buscar en los sitios sugeridos, los resultados no fueron favorables y por tanto en un grupo no se utilizaron REA ni OA. De acuerdo con DeVries (2013), aunque existen diferentes movimientos encaminados hacia las prácticas de uso de recursos abiertos, son pocas las instituciones que desean no solo publicar sino reutilizar el contenido de REA ofrecido bajo licencias abiertas. Por lo tanto, existe un área de oportunidad para seleccionar y tal vez traducir y adecuar contenido abierto (REA u OA) para el nivel de educación primaria.

Por último, existen áreas de oportunidad de los docentes en cuanto a saber integrar los recursos digitales abiertos sin conexión a Internet. Se identificó como un área importante en este estudio pues uno de los grupos tuvo fallas técnicas en la revisión de un REA y el docente optó por revisar una actividad del libro de texto por la falta de conocimiento sobre cómo integrar los recursos sin conexión a Internet. De acuerdo con Atkins, Brown y Hammond (2007) los REA se identifican como cursos completos, materiales de cursos, módulos, libros, videos, exámenes, softwares y cualquier otra herramienta, materiales o técnicas empleadas para dar soporte al acceso de conocimiento y que pueden ser utilizados y reutilizados. De tal forma que el docente

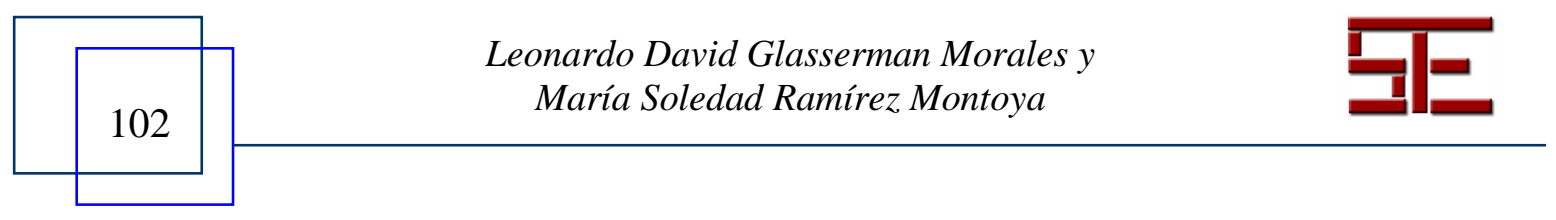




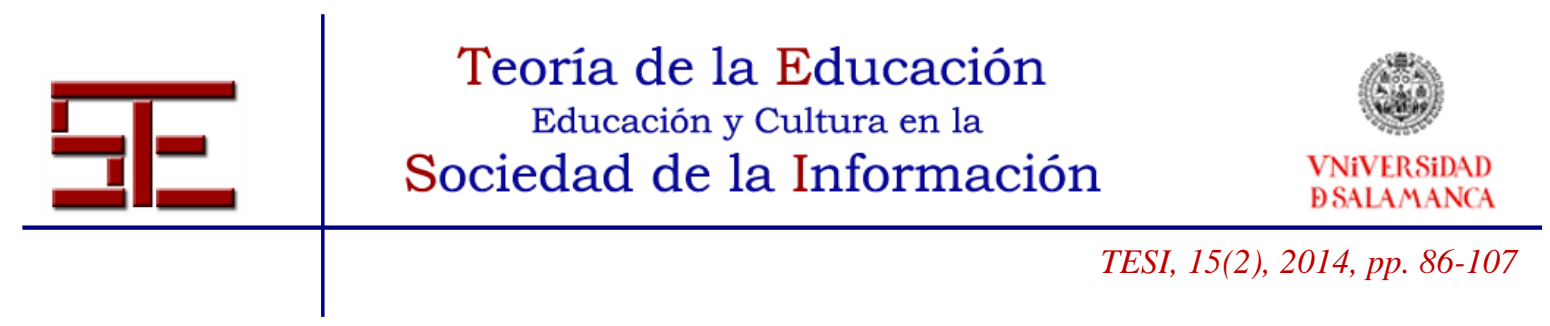

tiene que apropiar el concepto y poder sacarle el mejor provecho al recurso aun y cuando no disponga de Internet. Puede adecuar el contenido de un REA y adaptarlo para ser trabajado en un ambiente presencial sin apoyo de recursos tecnológicos, pero que la naturaleza del contenido provino de un REA.

\section{7.- CONCLUSIONES}

Con base en la pregunta de investigación del estudio: ¿Cuáles son los retos y oportunidades que tienen los profesores de educación básica al integrar REA y OA en sus procesos formativos para incentivar el aprendizaje activo?, se encontró que los docentes están familiarizados con el uso de recursos tecnológicos en el aula, sin embargo, no conocen acerca de los licenciamientos y las ventajas de apoyarse en recursos como los REA y OA para utilizarlos y reutilizarlos en diferentes contextos. Cabe mencionar que una vez que los docentes tuvieron conocimiento de los REA y OA, así como de los repositorios y de catálogos donde se alojan, pudieron realizar ejercicios para obtener recursos como material didáctico para su práctica docente. Se pudo observar cómo se utilizan los REA en el aula y se detectó que no en todos los repositorios propuestos se pudieron encontrar los recursos que se requerían.

Es sumamente importante dar a conocer a los docentes de todos los niveles las alternativas que tienen a su disposición para obtener recursos digitales con licenciamiento abierto como apoyo para su planeación didáctica. Difundir portales como los que se presentaron en este estudio permitirá que los docentes conozcan otras fuentes de información con recursos de calidad y con respeto a los derechos de autor y de esta forma incluirlos en el denominado movimiento educativo abierto. Una estrategia para dar a conocer estos portales podría ser mediante la difusión a través de sitios oficiales, o bien, a través de medios más informales como las redes sociales.

Los resultados de esta investigación sirvieron para apoyar en la comprensión de los docentes que están en la práctica sobre cómo podrían utilizar los REA y OA. Asimismo, los resultados contribuyeron a desarrollar una guía de usuarios para el metaconector (Educonector.info) del macroproyecto del que se desprendió esta investigación. La información puede ser útil para futuras investigaciones en donde se contemplen más instituciones, en otros contextos o en otros niveles escolares. Asimismo, se deben realizar estudios adicionales que se enfoquen en la evaluación de REA y OA para fomentar el aprendizaje activo en diferentes niveles educativos para seguir incrementando el saber en la temática.

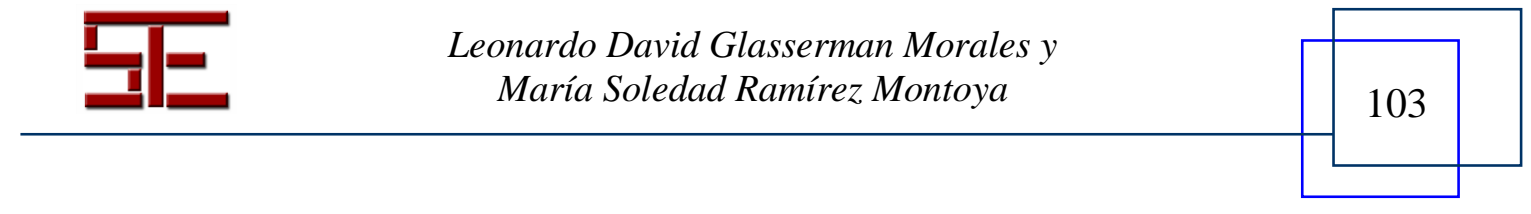




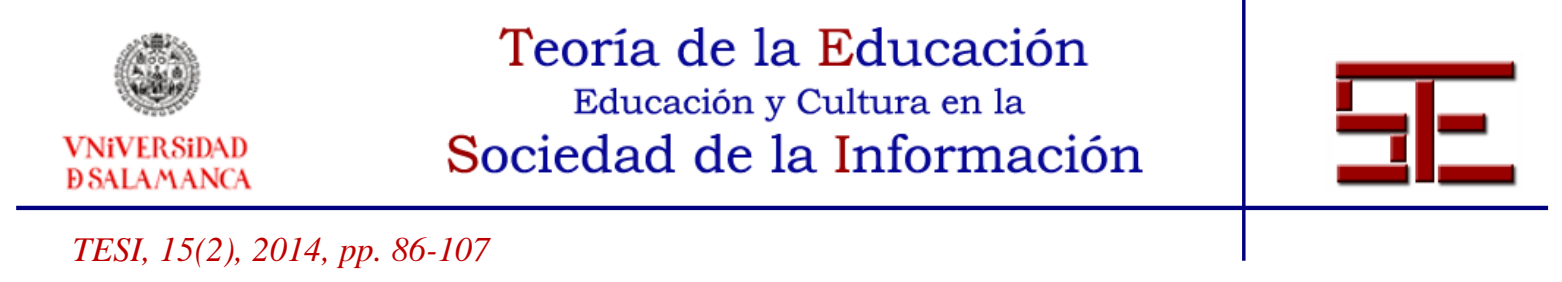

\section{8.- REFERENCIAS}

Atkins, D. Brown, J. \& Hammond, A. (2007). Report to the William and Flora Hewlett Foundation. Extraído el 02 de diciembre, 2011, de http://www.hewlett.org/oer.

Ávila, P. (2008). Recursos Educativos Abiertos, su importancia y valor social. Cognición Revista Científica de Flead. Extraído el 29 de noviembre, 2011, de http://216.75.15.111/ cognicion/index.php?option=com_content\&task=view\&id $=159 \&$ Itemid $=103$.

Celaya, R., Lozano, F. \& Ramírez, M. S. (2009). Apropiación tecnológica en profesores que incorporan recursos educativos abiertos en educación media superior. Revista Mexicana de Investigación Educativa, 15 (45), 487-513.

Correa, J. M. \& Martínez, A. (2010). ¿Qué hacen las escuelas innovadoras con la tecnología? Las TIC al servicio de la escuela y la comunidad en el colegio Amara Berri. TESI, 11 (3), 230-261.

Creswell, J. W. (2007). Qualitative inquiry and research design: Choosing among five approaches. ( $2^{\text {nd. }}$ Ed.). ThousandOaks, California, Estados Unidos: Sage.

Creswell, J. W. (2008). Educational research: Planning, conducting, and evaluating quantitative and qualitative research. Upper Saddle River, Nueva Jersey, Estados Unidos: Pearson Education.

D'Antoni, S. (2008). Open educational resources: the way forward. Deliberations of an international community of interest. Extraído el 28 de noviembre, 2011, de http://unesdoc.unesco.org/images/0015/001579/157987e.pdf.

Dillenbourg, P. (1999). What do you mean by collaborative leraning? En P. Dillenbourg (Ed.) Collaborative-learning: Cognitive and Computational Approaches (pp. 119). Oxford, Inglaterra: Elsevier.

DeVries, I. (2013). Evaluating open educational resources: Lessons learned. Procedia Social and Behavioral Sciences, 83, 56-60.

Downes, S. (2007). Models for sustainable Open Educational Resources. Interdisciplinary Journal of Knowledge and Learning Objects, 3, 29-44.

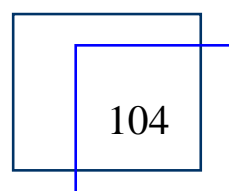

Leonardo David Glasserman Morales y María Soledad Ramírez Montoya 


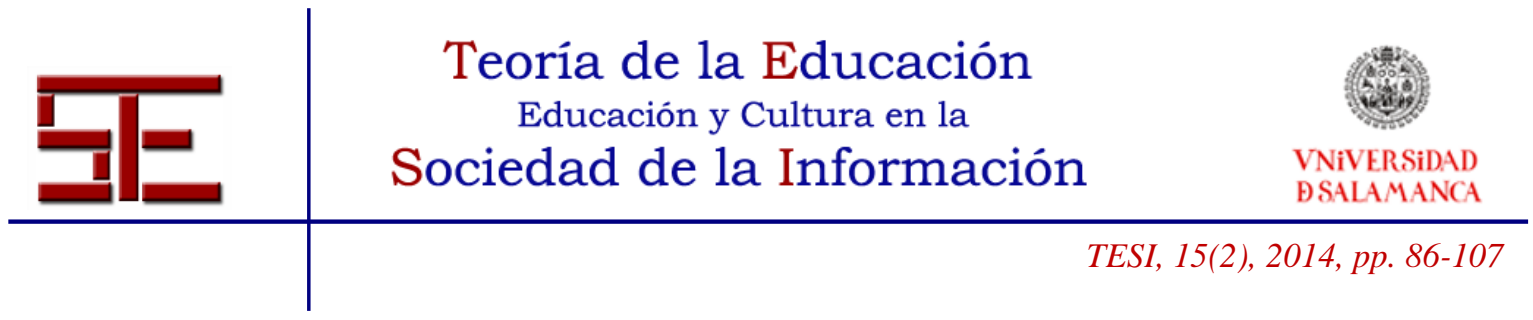

Enríquez, L. (2004). LCMS y Objetos de Aprendizaje. Revista Digital Universitaria, 5 (10), 2-9.

Expósito, J. \& Manzano, B. (2010). Áreas educativas interactivas, motivación y estrategias de aprendizaje, en educación primaria, a partir de un currículum modulado por nuevas tecnologías. TESI, 11 (3), 330-351.

Glasserman, L.D. (2012). Documentación de experiencias de una práctica educativa abierta (PEA) en un curso de educación superior. REICE: Revista Iberoamericana sobre Calidad, Eficacia y Cambio en Educación, 10 (2), 201211. Extraído el 16 de agosto, 2013, de http://www.redalyc.org/articulo.oa?id=55124596014.

Glasserman, L. D. (2013). Aprendizaje activo en ambientes enriquecidos con tecnología. Disertación doctoral. Tecnológico de Monterrey. Monterrey, Nuevo León, México. Extraído el 16 de agosto, 2013, de http://catedra.ruv.itesm.mx/handle/987654321/743

Glasserman, L. D., Ramírez, J. \& Juárez, J. E. (2013). Redes virtuales: Experiencia latinoamericana de una práctica educativa innovadora y eficiente. Revista de Investigación Educativa de la Escuela de Graduados en Educación, 3(6), 24-29. Extraído el 16 de agosto, 2013 de http://rieege.tecvirtual.mx/index.php/rieege/article/view/57

Heery, R. \& Anderson, S. (2005). Digital Repositories Review. Extraído el 01 de diciembre, 2011, de http://www.ukoln.ac.uk/repositories/publications/review200502/.

Kay, R. H. \& Knaack, L. (2008). A formative analysis of individual differences in the effectiveness of learning objects in secondary school. Computers \& Education, $51,1304-1320$.

Koopmann, F. K. (2002). Experiential civic learning by using "Projekt: Aktive Bürger". Recuperado el 25 de abril 2012, de http://www.jsse.org/2002/20022/pdf/koopmann-civic-learning-2-2002.pdf.

Mortera, F.J. (2011). Avances del Proyecto Metaconector de Repositorios Educativos para potenciar el uso de Objetos de Aprendizaje y Recursos Educativos Abiertos: Mejores Prácticas. Ponencia presentada en la Reunión de Primavera de CUDI 2011. Manzanillo, Colima, México.

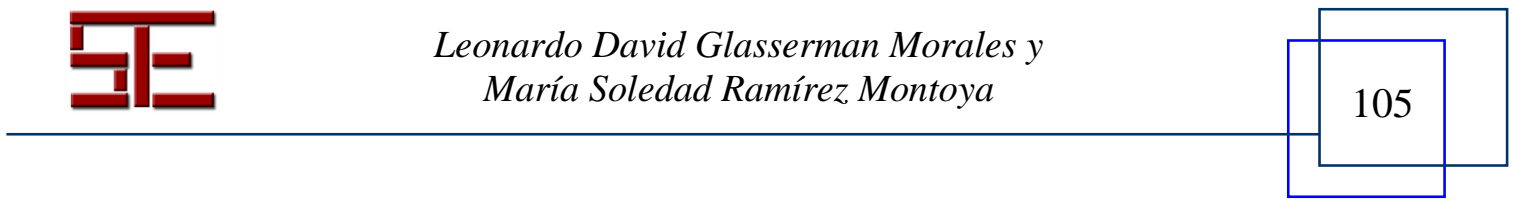




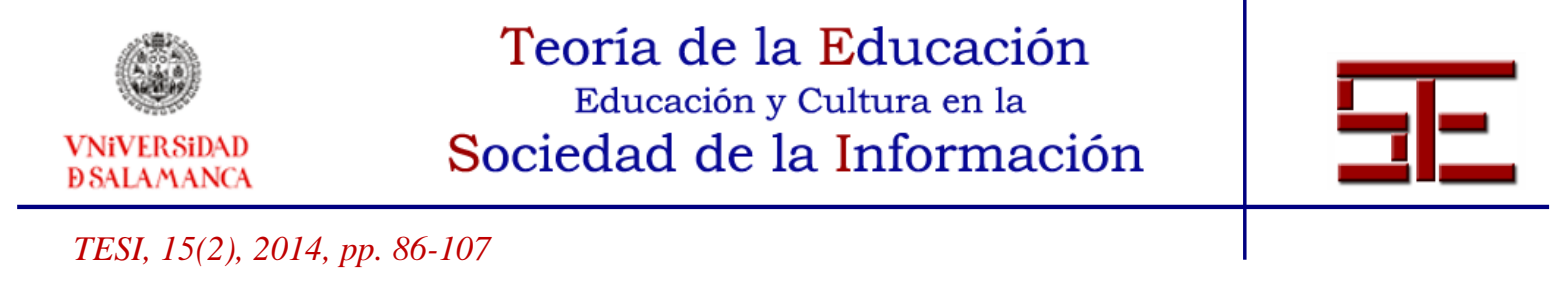

Mortera, F. J. \& Ramírez, M. S. (Coords.). Conexión de repositorios educativos digitales: educonector.info. Monterrey, Nuevo León, México: Lulú. Extraído el 03 de enero, 2014, de http://catedra.ruv.itesm.mx/handle/987654321/778.

Numagami, T. (1998). The infeasibility of invariant laws in management studies: a reflective dialogue in defense of case studies. Organization Science, 9, 3-15. Extraído el 07 de noviembre, 2011, de http://orgsci.journal.informs.org/content/9/1/1.full.pdf+html.

OPAL (2011). Beyond OER: Shifting Focus to Open Educational Practices. Extraído el 28 de noviembre, 2011, de http://oer-quality.org/.

Pagés-Arévalo, C. \& Lezcano, L. (2011). Social models in open learning object repositories: A simulation approach for sustainable collections. Simulation Modelling Practice and Theory, 19, 110-120.

Ramírez, M. S. (2013). Modelos y estrategias de enseñanza para ambientes Innovadores (ebook). Monterrey, Nuevo León, México: Editorial Digital del Tecnológico de Monterrey.

Ramírez, M. S. \& Burgos, J. V. (Coords.) (2010). Recursos educativos abiertos en ambientes enriquecidos con tecnología: Innovación en la práctica educativa. México: Lulú. Extraído el 16 de agosto, 2013, de http://catedra.ruv.itesm.mx/handle/987654321/566.

Ramírez, M. S. \& Burgos, J. V. (2011a). Towards a Culture of Openness in Education in Latin America. eLearning Papers, 23, 1-3. Extraído el 17 de agosto, 2013 de http://elearningpapers.eu/en/article/Towards-a-Culture-of-Openness-in-Education-inLatin-America?paper $=72110$.

Ramírez, M. S. y Burgos, J. V. (Coords.) (2011b). Transformando ambientes de aprendizaje en educación básica con recursos educativos abiertos. México: Lulú. Extraído el 16 de agosto, 2013 de http://catedra.ruv.itesm.mx/handle/987654321/393.

Sabiha, Y. (2012). An analysis on teachers' and teacher candidates' usage of internet based materials and awareness of learning objects. Procedia - Social and Behavioral Sciences, 46, 1914-1918.

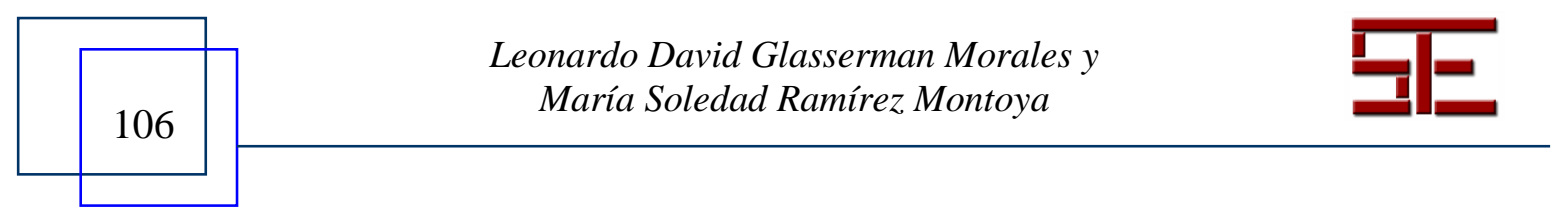




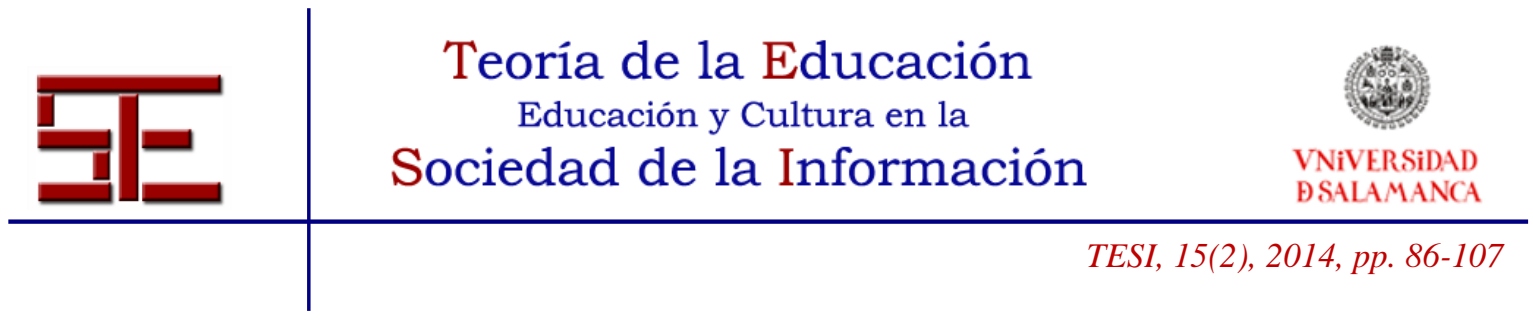

Spirer, J. (1980). The cases study method: Guidelines, practices, and applications for vocational education. Research and Development Series, 189.

Stake, R. E. (1995). Investigación con estudio de casos. Madrid, España: Morata.

Sutton, R. \& Barry, M.S. (1995). What theory is not. Administrative Science Quarterly, 40, 371-384. Extraído el 7 de noviembre, 2011, de http://www.jstor.org/pss/2393788.

TEMOA (2011). Portal de Recursos Educativos Abiertos. Extraído el 01 de diciembre, 2011,de http://www.temoa.info/es/acerca.

UNESCO (2002). Forum on the Impact of Open Courseware for Higher Education in Developing Countries Final report. Extraído el 23 de marzo, 2011, de http://unesdoc.unesco.org/images/0012/001285/128515e.pdf.

Valenzuela, J. R. \& Ramírez, M. S. (2010, junio). Trans-formando a los profesores: desarrollo de competencias para una Sociedad Basada en Conocimiento mediante objetos de aprendizaje abiertos. Ponencia presentada en el XI Encuentro Internacional Virtual Educa. Santo Domingo, República Dominicana.

Valverde, J., Garrido, M. C. \& Fernández, R. (2010). Enseñar y aprender con tecnologías: Un modelo teórico para las buenas prácticas con TIC. TESI, 11 (3), 203-229.

Wiley, D. (2000). Connecting learning objects to instructional design theory. Extraído el 24 de septiembre, 2011, de http://www.reusability.org/read.

Yin, R. K. (2003). Case study research, design and methods. ( $3^{\text {rd }}$ Ed.). Newbury Park, Estados Unidos: Sage.

Para citar el presente artículo puede utilizar la siguiente referencia:

Glasserman Morales, L. D. y Ramírez Montoya, M. S. (2014). Uso de recursos educativos abiertos (REA) y objetos de aprendizaje (OA) en educación básica. Revista Teoría de la Educación: Educación y Cultura en la Sociedad de la Información. 15(2), 86-107

[Fecha de consulta: dd/mm/aaaa].

http://campus.usal.es/ revistas_trabajo/index.php/revistatesi/article/view/11888

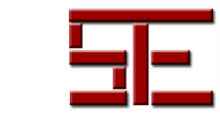

Leonardo David Glasserman Morales y María Soledad Ramírez Montoya 